\title{
032501
}

\section{MAPPING SURFACE COVER PARAMETERS USING AGGREGATION RULES AND REMOTELY SENSED COVER CLASSES}

\author{
Altaf M. Arain, W. James Shuttleworth, Z-Liang Yang \\ (Department of Hydrology and Water Resources, The University of Arizona, Tucson, USA) \\ Jené Michaud \\ (Department of Geology, The University of Hawaii at Hilo, USA)
}

Johannes Dolman

(DLO-Winand Staring Center, Wageningen, Netherlands) 


\begin{abstract}
A coupled model, which combines the Biosphere-Atmosphere Transfer Scheme (BATS) with an advanced atmospheric boundary-layer model, was used to validate hypothetical aggregation rules for BATS-specific surface cover parameters. The model was initialized and tested with observations from the Anglo-Brazilian Amazonian Climate Observational Study and used to simulate surface fluxes for rain forest and pasture mixes at a site near Manaus in Brazil. The aggregation rules are shown to estimate parameters which give area-average surface fluxes similar to those calculated with explicit representation of forest and pasture patches for a range of meteorological and surface conditions relevant to this site, but the agreement deteriorates somewhat when there are large patch-to-patch differences in soil moisture. The aggregation rules, validated as above, were then applied to remotely sensed $1 \mathrm{~km}$ land cover data set to obtain gridaverage values of BATS vegetation parameters for $2.8^{\circ} \times 2.8^{\circ}$ and $1^{\circ} \times 1^{\circ}$ grids within the conterminous United States. There are significant differences in key vegetation parameters (aerodynamic roughness length, albedo, leaf area index, and stomatal resistance) when aggregate parameters are compared to parameters for the single, dominant cover within the grid. However, the surface energy fluxes calculated by stand-alone BATS with the 2-year forcing data from the International Satellite Land Surface Climatology Project (ISLSCP) CDROM were reasonably similar using aggregate-vegetation parameters and dominant-cover parameters, but there were some significant differences, particularly in the western USA.
\end{abstract}




\section{Introduction}

Natural surfaces vary from place to place with a scale of heterogeneity which ranges from a few meters to hundreds of kilometers. Parameterizing such heterogeneous land surfaces in weather and climate prediction models is problematic because the grid square typically represents an area between $10^{4}$ and $10^{6} \mathrm{~km}^{2}$. In recent years, efforts have been made to improve the description of heterogeneous land surfaces in these models and there has been progress towards defining averaging procedures to calculate area-average land surface exchanges at local and regional scales (Mason, 1988; Wood and Mason, 1991; Blyth et al., 1993; Lhomme et al., 1994; Lynn et. al., 1995; Raupach and Finnigan, 1995). However, only a few past studies (such as Noilhan and Lacarrére, 1995) have validated model performance against observations, and little research has used the land surface schemes actually in use within General Circulation Models (GCMs).

One way to describe heterogeneous vegetation is to make a calculation for each separate patch of vegetation. This can be done by the 'mosaic' approach, in which separate models are used to estimate the fluxes for each patch at each time step and an appropriately weighted average value is then taken (e.g. Koster and Suarez, 1992). Recently Raupach and Finnigan (1995) have shown theoretically that, providing the surface energy partition for each patch is represented with the Penman-Monteith equation (Monteith, 1965), it may, in principle, be possible to simplify this approach by averaging appropriately chosen combinations of the surface and aerodynamic resistances used in that equation. However, despite the theoretical elegance of Raupach and Finnigan's simplification, it does not fundamentally alter the computational demand associated with representing an area of heterogeneous cover. For each separate patch the value of the surface 
and aerodynamic resistances are both related to transient weather variables, and they must be still individually evaluated and then averaged at each time step. Moreover, surface resistance is often related to the local soil moisture status--suggesting the need to retain a separate water balance for each patch, while aerodynamic resistance depends on local atmospheric stability--suggesting the need to retain an individual calculation of the transient surface energy balance for each patch.

A second approach to represent heterogeneous vegetation involves a greater level of approximation. In it a standard land-surface scheme is used with effective, area-average vegetation parameters calculated using simple aggregation rules applied to all the vegetation cover types present in the grid element. Aggregation rules (Shuttleworth, 1991) are simple averaging procedures to calculate effective values of surface cover parameters which estimate area-average surface fluxes similar to those given with explicit representation of the separate patches of vegetation. A weighted linear average of surface-cover parameters based on the fractional area of all the cover types present in the grid is the simplest averaging procedure, but if fluxes are not proportional to parameters (such as the aerodynamic roughness length), then linear averaging is inappropriate.

This second approach is different to that of Koster and Suarez (1991) or Raupach and Finnigan (1995) in that flux (or resistance) averaging is not necessary at each time step, rather it is done once at the beginning of the model run or, in the case of parameters which vary with season, once every week (say). Moreover, at each model time step the values of the important surface controls (such as surface and aerodynamic resistance) which are implicit or explicit in a land surface scheme are not evaluated using transient weather variables for each separate patch. One 
calculation of their area-average value is made and this is applied to describe the whole grid assuming that the relevant area-average parameters given by the aggregation rules apply. Theoretical justification for this second, more approximate approach to provide aggregate representation is much less tractable and so model experiments are used to explore the acceptability of the hypothetical aggregation rules to be used to average parameters appropriate for a particular land surface scheme. The first part of this paper describes such a model experiment carried out for the Biosphere-Atmosphere Transfer Scheme (BATS, Dickinson et al., 1993).

BATS is the land-surface parameterization used in the National Center for Atmospheric Research's (NCAR's) Community Climate Model. In normal application of BATS, the values of vegetation parameters are based on the single dominant surface-cover in each grid cell. A set of hypothetical aggregation rules for BATS surface cover parameters are given in Table 1 (Arain et al., 1996). Linear averaging is proposed for all parameters except aerodynamic roughness length and minimum stomatal resistance. The aggregate value of aerodynamic roughness length is calculated by averaging the drag coefficient from Mason (1988). Table 1 also shows the three alternative averaging procedures that have been proposed for minimum stomatal resistance: linear averaging, reciprocal averaging, and average of these two averages.

Arain et al. (1996) coupled BATS with an advanced, two-dimensional model of the atmospheric boundary-layer first developed by Mason and Sykes (1980) to obtain a realistic coupled model of surface-atmosphere exchanges. This model, hereafter called the BATS-ABL model, was used to investigate the acceptability and applicability of aggregation rules for BATS vegetation 
parameters using observed forcing and surface data from the First International Satellite Land Surface Climatology Project Field Experiment (FIFE) site in Kansas (Sellers et al., 1992). The results showed that the aggregation rules successfully calculate area-average surface fluxes under a variety of hydrometeorological conditions at this site. However, they did not work well when artificially wet (irrigated) patches were combined with naturally dry soil patches.

In the Arain et al. (1996) study, the application of aggregation rules for some important BATS parameters such as aerodynamic roughness length, zero plane displacement height, and minimum stomatal resistance was poorly tested because there is little difference in these parameters for the cover classes relevant to the FIFE site. Therefore it is appropriate to extend aggregation tests to those mixes of vegetation which have a large contrast in these three parameters. Cleared areas within undisturbed Amazonian forest provide the desired contrast. The results of aggregation tests carried out for adjacent patches of Amazonian evergreen broadleaf trees and short grass are presented in Section 2 of this report. Observed data used for model initiation, forcing, and validation were obtained from the Anglo-Brazilian Climate Observational Study (ABRACOS: Shuttleworth et al., 1991).

On the basis of the success reported in the current (and previous) study, the BATS-specific aggregation rules were then applied to the $1 \mathrm{~km}$ land-cover data set of Loveland et al. (1991) to calculate grid-average values of BATS vegetation parameters for $2.8^{\circ} \times 2.8^{\circ}$ and $1^{\circ} \times 1^{\circ}$ grid squares across the conterminous United States (U.S.). A comparison of the ensuing aggregate parameters with parameter values given by the conventional dominant cover within a grid cell is described in Section 3. In Section 4, the forcing data from the International Satellite Land Surface 
Climatology Project (ISLSCP) "Initiative 1" (Meeson et al., 1995) are used to conduct 2-year BATS simulations for the conterminous U.S. at a $1^{\circ}$ resolution. Fluxes from aggregate parameters are compared to fluxes from parameters based on the dominant vegetation type in each grid.

\section{Testing Aggregation Rules in the Amazon}

\subsection{The ABRACOS Experiment}

The ABRACOS sought to improve the parameterization of surface-atmosphere models by providing accurate and representative data for forested and deforested areas in the Amazon. Detailed studies of surface climatology, micrometeorology, plant physiology, and soil hydrology were made at three different forest and adjacent clearing sites across the Amazon (Shuttleworth et al., 1991; Gash et al., 1996).

Data from the Reserva Duke forest site and Fazenda Dimona pasture site, which are located respectively about 25 and $100 \mathrm{~km}$ from Manaus, Amazonas, were used in the current study. Reserva Duke $\left(2^{\circ} 57^{\prime} \mathrm{S}, 59^{\circ} 57^{\prime} \mathrm{W}\right)$ is a protected area, and the experimental site is surrounded by undisturbed forest for at least $5 \mathrm{~km}$ in all directions. The mean canopy height is $35 \mathrm{~m}$, but some trees reach $40 \mathrm{~m}$, and meteorological data were collected at the top of a $45 \mathrm{~m}$ tower. Detailed descriptions of the site and measurements have been given by Shuttleworth et al. (1984), Roberts et al. (1990), and Shuttleworth et al. (1991). Fazenda Dimona $\left(2^{\circ} 19^{\prime} \mathrm{S}, 60^{\circ} 19^{\prime} \mathrm{W}\right)$ is a $10 \mathrm{~km}^{2}$ 
forest clearing which was created by felling and burning the original forest and then planting pasture grasses (such as Brachiaria decumbens and Brachiaria humidicola) 12 years before the measurements were taken at this site. About $11 \%$ of the total area is bare soil, while $5 \%$ area is covered with tree trunks (Wright et al., 1992).

For logistic reasons, soil moisture data were recorded at a forest site near the Fazenda Dimona pasture site rather than at the Reserva Duke site. The soil at Fazenda Dimona is a yellow Latosol (Oxisol or Haplic Acrorthox) with $80 \%$ fine clay content and high conductivity (Wright et al., 1996). The soil moisture data were collected weekly at $20 \mathrm{~cm}$ intervals to a depth of $2 \mathrm{~m}$ using neutron probes. Hourly measurements of incident solar radiation, wind speed, air temperature, specific humidity, and precipitation were made with automatic weather stations. Net radiation $(\mathrm{Rn})$, sensible heat $(\mathrm{Hs})$, latent heat (LE), and ground heat $(\mathrm{G})$ fluxes were also measured at the pasture site, while only net radiation and ground heat flux were recorded at the forest site. Fluxes at the pasture site were recorded by a $9 \mathrm{~m}$ profile of aspirated psychrometers. These fluxes were in good agreement with measurements made with eddy correlation system and the Bowen ratio system during a 50 day sample period and the local energy budget was closed (Wright et al., 1992). At both sites, data collection started in mid-September 1990 , and continued until midSeptember 1991, although there were times when some of the meteorological and soil moisture data were missing at one or both sites during this period. 


\subsection{Validation of BATS at the Amazon Sites}

Short grass and evergreen broadleaf trees are the appropriate BATS surface cover classes for the pasture and forest site, respectively. The corresponding set of morphological, physical and biophysical parameters are given in Table 2. Based on ABRACOS observations (Wright et al., 1996), soil textural class 10 [within a range of 1 (sand) and 12 (clay)] and soil color class 7 [within a range of 1 (light) and 8 (dark)] were selected as suitable for the Manaus site. The associated soil parameter values are given in Table 3.

A stand-alone version of BATS was run using the observed hourly values of incident solar radiation, air temperature, specific humidity, wind velocity, and precipitation as forcing data. It is necessary to initiate nine state variables (see Table 4). Surface soil temperature, deep soil temperature, canopy temperature, and canopy air temperature were all initialized to observed air temperature in BATS. The ground wetness factor was set to 1, while the volumetric soil moisture in the three BATS soil layers (upper $0.1 \mathrm{~m}$, rooting $1-1.5 \mathrm{~m}$ and total $10 \mathrm{~m}$ ) was obtained by linear interpolation of the observed soil moisture data. The soil moisture values observed at $2 \mathrm{~m}$ were assumed to be the same as at $10 \mathrm{~m}$, which is the depth of the lowest BATS soil layer.

Surface flux data for the pasture site were available for validation for 27 days ( 9 October - 5 November) in 1990 and 71 days (2 July - 11 September) in 1991. Measurement period during 1990 was typically dry, while the 1991 dry season was more typically wet (Wright et al. 1996). When the above-described default parameters were used in the stand-alone version of BATS, the calculated latent heat fluxes were, on the average, $38 \mathrm{Wm}^{-2}$ too low, while sensible heat fluxes 
were too high by $18 \mathrm{Wm}^{-2}$. The root mean squared error between 30 -minute model estimates and observations of these fluxes were $82 \mathrm{Wm}^{-2}$ and $57-\mathrm{Wm}^{-2}$, respectively (see Table 5a). In this study, the philosophy adopted was to make the minimum parameter changes necessary to achieve acceptable agreement between observations and model calculations. In practice, the simulations of the pasture energy fluxes were greatly improved merely by changing the value of minimum stomatal resistance from $200 \mathrm{sm}^{-1}$ to $40 \mathrm{sm}^{-1}$, which is consistent with observations made at this pasture site [Wright et al. (1996) suggest calculating surface conductance (in $\mathrm{mm} \mathrm{s}^{-1}$ ) using leaf area index (minimum value 1.2 at this site) multiplied by $21.5 \mathrm{~mm} \mathrm{~s}^{-1}$ ]. With this change in minimum stomatal resistance, the mean bias was reduced to $11 \mathrm{Wm}^{-2}$ for latent heat and $4 \mathrm{Wm}^{-2}$ for sensible heat, while the corresponding root mean squared errors reduced to 54 and $40 \mathrm{Wm}^{-2}$, respectively (see Table 5b). These improvements are illustrated in Figure 1a-b for July 21, 1991, a day on which the soil moisture was fairly high.

Forest validation runs were also performed over the two time intervals, 3 October 1990 to 31 January 1991 and 1 July 1991 to 26 September 1991, these being the times when both soil moisture and meteorological forcing data were available at the Reserva Ducke forest site. Although surface heat fluxes were not available at this site for this period, other studies for forested areas in the Amazon (Shuttleworth, 1988; Wright et al. 1996) have shown that, on the average, about $80 \%$ of the available energy is used for transpiration and that there is no substantial decrease in evapotranspiration during low rainfall periods. BATS simulations using default parameters gave latent heat fluxes which were too small during periods of low rainfall. 
The default parameters for evergreen broadleaf forests (given in Table 2) assume the rooting depth for forest cover is $1.5 \mathrm{~m}$ and that $80 \%$ of these roots are in the upper $10 \mathrm{~cm}$ of soil. However, there is strong field evidence (e.g., Hodnett et al., 1995; Nepstad et al., 1994) that forest roots penetrate and extract water to depths of at least $3.5 \mathrm{~m}$ in the Amazon. To reflect this, the depth of the rooting zone in BATS was increased from $1.5 \mathrm{~m}$ to $4.0 \mathrm{~m}$, and the distribution of roots was changed so that only $20 \%$ (rather than $80 \%$ ) of roots were assigned to the upper $10 \mathrm{~cm}$ deep soil layer. This change greatly improved the simulated surface fluxes for the forest in dry conditions. These improvements are shown in Figures lc-d.

The aggregation studies described in the next section were made using both the original "default" parameters and the revised parameters to establish the sensitivity or otherwise to the assumed parameter values.

\subsection{Aggregation Studies}

\subsubsection{Procedures}

The procedures used to test aggregation rules were essentially identical to those described in detail by Arain et al. (1996). Two versions of the BATS-ABL model were compared: one with explicit representation of a $1-\mathrm{km}$ long pasture adjacent to a $1-\mathrm{km}$ long forest, and one in which vegetation is a homogeneous blend of pasture and forest. In the homogeneous case, vegetation parameter values were based on the aggregation rules listed in Table 1 applied to a 50\% pasture, $50 \%$ forest mix. The selection of patch and domain size depends on the natural heterogeneity of 
the area under consideration and numerical characteristics of the model. Model experiments at the FIFE site (Arain et al., 1996) showed that simulated fluxes were not very sensitive to the modeled domain and patch sizes, and that $1 \mathrm{~km}$ patches in a $2 \mathrm{~km}$ domain are plausible scales of patch variability. Both versions of the model were initiated with identical observed meteorological and soil moisture data and were run forward for short periods at particular times (e.g. a.m., noon, p.m.) on selected days to allow the modeled atmosphere to come into equilibrium with the modeled surface, thus providing a 'snap shot' of the difference in surfaceatmosphere interactions with and without explicit representation of the vegetation patches. A comparison was then made between model-calculated area-average energy fluxes of the heterogeneous and homogeneous models. The level of agreement between these two different calculations is then used to evaluate the performance of the aggregation rules.

In practice, the simulated fluxes (especially those of ground heat flux) are sensitive to the initial assignment of deep soil temperature because the model is run forward only for a short period of time. Hence, the initial state variables used in the model (see Table 4) were obtained by selecting the required values at appropriate times from multi-month stand-alone BATS simulations for pasture, forest, and aggregate-vegetation.

The interface height between BATS and the atmospheric boundary-layer model was set to $45 \mathrm{~m}$. Initial vertical profiles of potential temperature, humidity, and wind speed were generated by running a one-dimensional version of BATS-ABL model forward for several hours with fixed surface conditions until the calculated values of these atmospheric variables matched the observation $45 \mathrm{~m}$ above the ground at the forest site. It was assumed that the remainder of 
calculated vertical profiles were then in equilibrium with area-average surface exchanges. The integrating time of the BATS-ABL model depended- on the amount of surface variation and the spatial dimension of the variation, but typically corresponded to 10 minutes. For a detailed discussion on the sensitivity of simulated surface fluxes to the choice of this model interface height, and details of BATS and ABL model components, the reader is referred to Arain et al. (1996), Arain (1994), Blyth et al. (1993), Dickinson et al. (1993), Wood and Mason (1991), and Mason (1988).

\subsubsection{Results}

Two-patch and corresponding aggregate-cover simulations using the BATS-ABL model were made on five cloud-free days three times a day: one mid-morning, one close to noon, and one mid-afternoon (see Table 6). Many aspects of climate are fairly similar throughout the year at this ABRACOS site, but rainfall is seasonal. By chance, one dry period during the 1990 data collection was much longer than is usual, and this gave an excellent opportunity to observe effects of dry periods on aggregate surface behavior with these two very different surface vegetation covers. Two study days were selected from this unusually dry period and three from a more typical wet period--these judgments being based on the observed soil moisture. The midday observed soil moisture values in the upper $0.1 \mathrm{~m}$ soil layer and in the $1 \mathrm{~m}$ rooting layer are given in Table 6.

October 26, 1990 was a hot, sunny day when the soil moisture in the rooting zone was low. Simulated evaporative flux from the forested area was large and showed no evidence of soil 
moisture stress because of the deeper roots, while evaporation from the pasture patch was low. In the BATS-ABL model, the corresponding aggregate vegetation cover also did not show evidence of soil moisture stress because of its (assumed) $2.5 \mathrm{~m}$ deep rooting depth. The simulated twopatch and aggregate-cover area-average energy fluxes were noticeably different on this day, especially for the noon and mid-afternoon runs. October 30, 1990 was also a dry day with low soil moisture in the rooting zone, and the difference in evaporative flux from forest and pasture patches was again as large as $271 \mathrm{Wm}^{-2}$ at mid-day. In fact, the pasture patch was close to wilting point, while there was still plenty of water available for evaporation in the deeper-rooted forest patch. The variation in sensible heat (Hs), latent heat (LE), ground heat $(\mathrm{G})$, and momentum flux (M) across the modeled domain from two-patch and homogeneous cover is shown in Figure 2. The increase in the momentum flux at the left edge of the forest patch (located in the middle) is because of the sudden increase in the aerodynamic surface roughness (see Figure $2 \mathrm{~d}$ ). This perturbation at the left edge of forest patch is canceled (in terms of area average) by an decrease in momentum at the right edge. The differences between patch average and aggregate fluxes were also significant (up to $25 \mathrm{Wm}^{-2}$ ).

December 10, 1990 was a wet day at the beginning of the rainy season in this part of the Amazon. Soil moisture at the pasture site was sufficiently high to essentially eliminate the soilmoisture control on transpiration, so that the pasture was evaporating at close to potential rate. The two-patch and aggregate-cover area-average energy fluxes were similar for all three runs on this day. The last two days on which BATS-ABL runs were made, July 3 and August 28, 1991, were days with high soil moisture. The evaporative fluxes from both the pasture and forest 
patches were large, and the latent heat from aggregate cover was also high. The proposed BATSrelevant aggregation rules again worked well at all three times on these two days.

Comparison of patch-average and corresponding aggregate sensible heat, latent heat, ground heat and momentum flux for all 15 BATS-ABL runs is given in Figure 3. In these runs, the revised vegetation parameters were used (see Section 2.2). This figure shows that the aggregation rules worked quite well when neither of the vegetation patches has soil moisture stress, but agreement between two-patch and aggregate-cover area-average fluxes deteriorates somewhat when one of the patches (the shorter-rooted pasture patch) is subject to soil moisture stress. The four outliers of latent heat flux in Figure 3b correspond to the noon and afternoon model runs on October 26, 1990 and October 30, 1990. Two-patch and corresponding aggregate-cover runs were also performed for the above-mentioned days and times using the BATS default vegetation parameters. The results (not shown in this paper) are similar.

Hence, the overall results of model experiments at the ABRACOS (Manaus) site are in essence the same as those reported by Arain et al. (1996) for the FIFE site. At the FIFE site, aggregation rules did not work well when dry soil moisture patches were combined with artificially wet (irrigated) patches. They also perform less well at the ABRACOS site when there is a large soil moisture deficit in the shallower-rooted pasture patch, while the forest patch (with deeper roots) still has access to a substantial moisture store.

In order to investigate the sensitivity of aggregation rules to large differences in soil moisture in adjacent patches in greater detail, the stand-alone BATS runs for forest and pasture patches were 
compared with a run for the corresponding aggregate cover using observed forcing data at the Reserva Duke forest site. Figures $4 \mathrm{a}-\mathrm{b}$ show daily average energy fluxes from two-patch and corresponding aggregate-cover runs for periods with dry and wet soils, while Figure $4 c$ shows the wilting factors (calculated within the BATS model for upper and root soil layers using observed soil moisture in corresponding soil layers) for both pasture and forest patches for the entire study period. The plant wilting factor $\left(\mathrm{W}_{\mathrm{LT}}^{\mathrm{i}}\right)$ as defined by Dickinson et al. (1993) is given by:

$$
w_{L T}^{i}=\frac{\left(s_{i}\right)^{-B}-1}{\left(s_{w}\right)^{-B}-1}
$$

where $s_{i}$ is the ratio of volumetric soil water to that at saturation for ith soil layer, and $s_{w}$ is the ratio of volumetric soil water to that at the permanent wilting point (i.e., when suction reaches 15 bars), while $\mathrm{B}(=9.2)$ is the exponent which defines the change in soil water potential and hydraulic conductivity with soil moisture (Clapp and Hornberger, 1978). The $\mathrm{W}_{\mathrm{LT}}^{\mathrm{i}}$ ranges from 0 at saturation and 1 at the permanent wilting point.

As expected, the differences in sensible heat, latent heat, and ground heat flux between heterogeneous and aggregate cover is most pronounced during the time period when there was a large soil moisture deficit (see Figure $4 \mathrm{a}$ and $4 \mathrm{c}$ ). In fact, the upper soil is close to the wilting point for both the pasture and forest during this unusually dry period. In the rooting zone, however, the pasture is water stressed and the forest is not. Because there is a non-linear relationship between the wilting factor and soil moisture content given in Equation (1), the average root soil moisture does not lead to the average wilting factor. However, it is reassuring to note that, even with this extreme difference in cover type (resulting in a four-fold difference in rooting depth), the discrepancy between daily average surface energy fluxes is still only about 
$10 \%$ or $10 \mathrm{Wm}^{-2}$ in dry soil conditions which are, at least in the case of this particular ABRACOS study site, uncommon and short-lived.

Table 1 gives three alternative aggregation rules for combining minimum stomatal resistance, these being linear averaging, reciprocal averaging and, following the suggestion of Blyth et al. (1993), the average of these last two averages. Evaluation of their relative merits can be made at this ABRACOS site because applying these three rules with the preferred value of minimum stomatal resistance for short grass $\left(40 \mathrm{sm}^{-1}\right)$ and evergreen forest $\left(150 \mathrm{sm}^{-1}\right)$ gives the values of 95,63 , and $79 \mathrm{sm}^{-1}$, respectively. Model runs were made using both BATS-ABL and the standalone version of BATS with these three alternative values for the aggregate value of minimum stomatal resistance. Typical results for the stand-alone BATS model are illustrated in Figure 5. Figure 5a shows calculated fluxes on October 30, 1990, a day with dry soil, and Figure 5b shows calculated fluxes on August 28, 1991, a day with wet soil. Applying the three alternative rules gave results which (although not good) are very similar to each other when soils are dry; however in more common wet soil conditions, the linear aggregation rule consistently performed best. Similar results were obtained from simulations using the coupled BATS-ABL model on the five days and three times of the day for which tests were made. On the basis of this evidence, a linear aggregation rule is recommended for this BATS parameter, and linear aggregation of minimum stomatal resistance was adopted and applied for the remainder of the analysis described below. 


\section{Application of Aggregation Rules for USA}

Results for the ABRACOS site and those reported by Arain et al. (1996) for the FIFE site suggest that the proposed BATS-specific aggregation rules given in Table 1 calculate area-average energy fluxes that are acceptably similar to those calculated with explicit representation of separate vegetation patches under a wide range of hydrometeorological conditions and for a range of surface covers appropriate to these two sites. Shortcomings can arise, but these are not because of patch-to-patch differences in the vegetation-related parameters per se; rather, they occur if there are marked differences in the plant-accessible soil moisture in the heterogeneous landscape (such as irrigated patches in dry landscape or short rooted pasture patches in forest areas), and they arise because the root resistance assumed in BATS is a non-linear function of soil moisture. However, an analysis of irrigated land falling within any individual grid square used in meteorological models shows that the proportion is rarely, if ever, greater than $10 \%$ in the USA--the USA being the only region for which satellite-derived data on land cover are readily available at this time. Moreover, coupled modeling studies using BATS-ABL show that including artificially irrigated vegetation with this relative extent still allows the use of aggregation rules with acceptable accuracy in the calculated area-average fluxes.

For the purposes of the remainder of this study, we chose to ignore this complicating, indirect influence of heterogeneous soil moisture acting through the overlying vegetation and proceed to investigate the sensitivity of surface parameters and exchanges under the assumption that the BATS-specific aggregation rules for vegetation parameters given in Table 1 have broader 
acceptability and applicability. However, the reader is cautioned that the following analysis is questionable in two specific cases, namely for landscapes and climates in which there are either (a) large differences in soil moisture and with wet and dry soils covering approximately equal areas and with soil moisture differences greater than $10-20 \%$ of the rooting zone soil moisture store; or (b) approximately equal areas of shallow-rooted and deep-rooted vegetation growing in a climate where the shallower-rooted vegetation is under soil moisture stress.

\subsection{The USGS/EDC Land Cover Data set}

A prototype land-cover characteristics data base for the conterminous United States is available from the U.S. Geological Survey (USGS) EROS Data Center (Loveland et al., 1991) for use in a variety of global modeling, mapping, monitoring, and analytical studies. These data were derived by classifying the 1990 NOAA-11 Advanced Very High Resolution Radiometer time-series data at $1 \mathrm{~km} \times 1 \mathrm{~km}$ resolution, with post-classification refinement based on other Earth science data including topography, climate, soils, and ecoregions. The data base uses the concept of seasonal land cover regions as a framework for presenting the temporal and spatial patterns of vegetation. A set of 28-day maximum Normalized Vegetation Difference Index (NDVI) composite images covering the conterminous United States were clustered into 70 spectral-temporal classes and subsequently stratified, refined, and labeled using the ancillary data. As a result, 159 seasonally distinct spectral-temporal land-cover classes were labeled according to their constituent vegetation types and, in the case of the data used in this study, these 159 classes were then translated into the 18 BATS-relevant cover classes. An additional nine classes were added which correspond to mixtures of two classes within a $1 \mathrm{~km} \mathrm{x} 1 \mathrm{~km}$ pixel. 


\subsection{Aggregate Parameters from Remotely Sensed Land Covers}

We obtained aggregate BATS parameter values for $2.8^{\circ} \mathrm{GCM}$ grids by computing the areaaverage of the $1 \mathrm{~km}$ BATS values obtained from the USGS-EROS land cover data base described above. Aggregate values of vegetation parameters (Table 3) were computed using the aggregation rules given in Table 1 (but assuming a linear aggregation rule for minimum stomatal resistance). In this section, the resulting parameter values are compared with the equivalent values for the single most common BATS vegetation cover present in the grid square, this being the method used for assigning parameters in GCMs at the present time. We used a grid size of $2.8^{\circ}$ latitude by $2.8^{\circ}$ longitude because this is the standard horizontal resolution of NCAR's Community Climate Model version 2 (CCM2) and is a typical resolution of other climate models.

The fractional cover area of all vegetation types within a given grid cell was calculated using the total number of $(1 \mathrm{~km} \times 1 \mathrm{~km})$ pixels for each cover class. In the case of cover types assigned a number 20-28 in the USGS-EROS data, $50 \%$ of the area of each pixel was assigned to be one cover type and $50 \%$ to the other cover type in these calculations. There can be up to eight cover classes in an individual $2.8^{\circ} \times 2.8^{\circ}$ grid square, but more typically there are 3-5 different BATS cover classes present. On the average, about $50 \%$ of the grid square is covered with the most common cover class, but rarely is the grid square entirely covered with one vegetation class. In some cases, the most common vegetation class covers only $20-30 \%$ of the grid. 
The percentage difference between the value of important BATS-specific vegetation parameters for the single cover currently assigned to each grid square in CCM2 and the value calculated for aggregate-cover using USGS-EROS data is illustrated in Figure 6. Maximum fractional vegetation cover is influenced little by using these different approaches of parameterization for most of the USA (see Figure 6a), but there are pronounced differences in some regions of the west. This is because the default cover assigned within CCM2 is semi-desert in these regions, but the remotely sensed data show the substantial presence of vegetation with higher vegetation cover fraction. In contrast, the values assigned to minimum stomatal resistance (Figure 6b) show significant differences in central and eastern portions of the USA, with the sign depending on whether more or less crop land (which is assumed to have lower stomatal resistance than other cover types in BATS) is included in the area-average calculation.

The calculated values of area-average albedo and warm season leaf area index (Figures 6c-d) also show marked differences, especially in the western United States. The use of default cover class assigned in CCM2, which is often short grass or shrub land, neglects the presence of other surface cover types such as desert and evergreen forest. However, the presence of these covers is reflected in the parameter values calculated for aggregate cover. The assigned values of cold season leaf area index and aerodynamic roughness length exhibit marked differences (of up to $\pm 100 \%$ ) across the entire United States (Figures 6e-f), but the spatial distribution of differences in these parameters is difficult to interpret.

Figure 7 is similar to Figure 6 except that aggregate parameters were computed for the $1^{\circ} \times 1^{\circ}$ (ISLSCP) grid mesh. In general terms, the percentage differences in parameter values follow a 
similar pattern to that calculated for the $2.8^{\circ} \times 2.8^{\circ}$ (CCM2) grid mesh, but it is easier to interrelate spatial patterns between parameters in the case of this smaller $1^{\circ} \times 1^{\circ}$ grid mesh. The most noticeable distinction between Figure 6 and Figure 7 occurs in the western United States for vegetation fraction, leaf area index, albedo, and minimum surface resistance. This distinction is not related to the use of aggregate covers, but is due to a mismatch between the single cover currently assigned within CCM2 and that measured from satellite.

\section{Simulations Using ISLSCP CDROM Data}

\subsection{Model Forcing Variables and Initiation}

The ISLSCP "Initiative 1" data set (Sellers et al., 1995; Meeson et al., 1995) is arguably the most spatially and temporally comprehensive, uniform and contiguous data currently available for land-surface modeling studies. This data set includes many of the fields required to prescribe boundary conditions, initiate state variables, and force land system models. Data are available for 1987 and 1988, and most are spatially continuous over Earth's land surface on a $1^{\circ} \times 1^{\circ}$ equalangle grid. The temporal frequency of the data set is monthly, but some important near-surface meteorological parameters are available as both 6-hourly and monthly means. Most of the nearsurface meteorological variables were extracted from the operational forecast analysis archive of the European Center for Medium-Range Weather Forecasts.

In BATS, air temperature, dew point temperature, surface pressure, wind velocity, precipitation, and downward short-wave and long-wave radiation are used as forcing variables, and these 
variables are available as 6-hourly time series on the ISLSCP CDROM. They were interpolated to provide hourly-mean values using a cubic spline interpolation method. The interpolated negative values of shortwave radiation were set to zero. The 6-hourly total precipitation was equally distributed as hourly values for that period. Saturated specific humidity was calculated from dew point temperature and surface pressure using Tetens formula (Riegel, 1974). Air temperature and dew point temperature were given at $2 \mathrm{~m}$ above the ground, while wind velocity was given at $10 \mathrm{~m}$. For consistency, the values of wind velocity were extrapolated to $2 \mathrm{~m}$ assuming a logarithmic wind profile.

Although soil texture data are provided in the ISLSCP CDROM, soil color classes are not provided; hence (for consistency), both soil texture and the soil color used in the stand-alone BATS simulations were taken from the Wilson (1984) data set. Selection of a set of soil parameters corresponding to these soil classes was then made following Dickinson et al. (1993). In each grid square, surface soil temperature, deep soil temperature, canopy temperature and canopy air temperature were all initialized to the observed air temperature in the stand alone BATS model. Soil moisture in the upper, root, and total soil layer was initialized to a fixed fraction of available soil storage, which in most grid squares corresponds to $60-75 \%$ of saturation, depending upon soil textural class. The ground wetness factor was set to 1. Because BATS output can be sensitive to initial state variables, the model was 'spun up' for 20 years (by cycling the observed forcing variables from first year of CDROM data set) before it was run forward to provide the results for 1987 and 1988 described below. 


\subsection{Model Results}

Figure 8 illustrates the calculated latent heat flux (left) and sensible heat flux (right) given by the stand-alone BATS simulations, using parameter values defined for each grid square for the most common cover in Figures 8a, 8c, 8e, and $8 \mathrm{~g}$ and using aggregation rules in Figures 8b, 8d, 8f, and $8 \mathrm{~h}$. The four panels at the top of the figure are average values calculated using forcing variables from the ISLSCP CDROM data set for June, July, and August 1988, while the four figures at the bottom of the page are the equivalent average values for December 1987 and January and February 1988. [Note: There was little obvious difference between fluxes calculated for equivalent seasons in 1987 and 1988 and, in comparison with the latent and sensible heat fluxes, the 3-month average ground heat flux calculated with both sets of parameters is everywhere very small in both winter and summer seasons.]

A distinctly regional behavior in terms of the calculated surface fluxes across the USA is illustrated in these figures. In summer, evaporation (Figures 8a-b) largely follows the distribution of precipitation across the country, and the eastern USA and gulf coast have significantly greater latent heat flux than the western USA. There is complementary behavior for sensible heat (Figures 8e-f) as might be expected from energy balance considerations. The east-west distinction persists in the winter season. Latent heat fluxes (Figures $8 \mathrm{c}-\mathrm{d}$ ) are again larger in the east than the west--although the distinction is less pronounced than in the summer, while sensible heat fluxes (Figures 8g-h) are calculated to be negative in the eastern USA but are positive and approximately equal to the latent heat flux in the western USA. The mean values of latent heat and sensible heat fluxes for summer season and winter season over entire domain (conterminous 
USA) were calculated for both single most common vegetation parameters and aggregate vegetation parameters. The maximum and minimum flux values corresponding to any grid square for each panel of Figure 8 were also calculated. The comparison of mean values and maximum and minimum values of latent heat and sensible heat fluxes for summer season and winter season using two approaches are given in Table 7. The mean vales from single dominant cover and aggregate cover are very similar although large differences were observed in the range of maximum and minimum flux values. The BATS simulated fluxes were also compared with estimated surface fluxes provided on the ISLSCP CDROM which were extracted from the European Center for Medium-Range Weather Forecast (ECMWF) operational forecast analysis archive (see Blondin, 1991 for details of ECMWF surface model). The geographical patterns of those fluxes were broadly similar to those shown in Figure 8 in summer, although the ISLSCP data include some suspiciously high latent heat fluxes in portions of the eastern United States. The sensible heat flux reported on the ISLSCP CDROM also has zones of sensible heat which run east-west in the winter, rather than north-south.

The differences between the surface heat fluxes calculated with parameters for the most common cover minus those calculated with aggregate cover are shown in Figure 9. Those on the left of the page (Figures 9a-b) are for latent heat, and those on the right side of the page (Figures 9c-d) are for sensible heat. The difference in calculated fluxes is within $\pm 10 \%$ in many locations and in both seasons. However there are significant differences in the sensible heat flux in the summer season (Figure 9c), which are particularly noticeable in parts of the western USA and are consistent with the large difference in surface albedo and leaf area index for the two parameterizations in this region. There is also an appreciable shift in the Bowen ratio in some 
parts of the eastern USA in winter months, with the aggregate parameters tending to give rather more latent heat but rather less sensible heat.

Figure 10 illustrates that the influence on calculated fluxes given by the two alternative parameterizations can differ greatly from one location to the next and that the different parameterizations can give persistent alteration in the calculated surface energy fluxes in specific locations. Figure 10a shows the monthly average latent heat and sensible heat fluxes for a grid cell in central Kansas, while Figure $10 \mathrm{~b}$ gives a grid cell in southern Arizona. In Kansas, there is little difference throughout the entire two-year period, but in Arizona including the influence of evergreen shrub land and semi-desert and, at higher elevations, evergreen trees, reduces the areaaverage albedo of aggregate cover and systematically increases the outgoing sensible heat flux because evaporation is water-limited in this region.

\section{Summary and Discussion}

Model experiments at the ABRACOS site (this study) and at the FIFE site (see Arain et al., 1996; Arain, 1994) using observations for validation and initiation, have given guidance on the aggregation rules appropriate to the BATS model. Linear aggregation rules work well for most of the vegetation-related parameters, including (on the basis of results for the ABRACOS site) minimum stomatal resistance. Aerodynamic roughness length is the exception: in this case, a logarithmic aggregation rule is required (Table 1). In the experiments conducted at the ABRACOS site and the FIFE site, the dominant responses were sufficiently linear that simple averaging was appropriate despite marked heterogeneity in surface fluxes from each patch. In 
general terms the theoretical work of Raupach and Finnigan (1995) also supports the linear averaging of surface cover parameters, albeit in their study for particular combinations of the surface and aerodynamic resistances used in the Penman-Monteith equation. The sensitivity of each vegetation parameter used to calculate area-average response of the BATS model was tested by Arain (1994). These tests showed that most sensitive parameters are fractional cover area, minimum stomatal resistance, and roughness length, while other BATS vegetation parameters had little effect on the averaging scheme. Experiments conducted at the ABRACOS site were effective tests of aggregation rules for stomatal resistance, aerodynamic roughness length, and zero plane displacement because there were large contrasts in these variables between the forest and pasture patches. The testing of key vegetation parameters at the ABRACOS helps to draw conclusion that linear aggregation is sufficient for most of the BATS parameters and a different set of input parameters corresponding the tested cover classes, would not alter the main conclusion of this study. Mixture of patches of tall and short crops are not uncommon in parts of the world where there has been human influence on land cover, and it is reassuring that aggregation rules for BATS' vegetation-related parameters can work within acceptable limits in this case.

However, both of the above-mentioned studies suggest that caution is necessary if aggregate representation is sought in a landscape where there are approximately equal areas with significant differences in plant-available soil moisture. Such differences may be man-made (by irrigation), but the proportion of irrigated land within a GCM grid is usually small and its influence on the area-average fluxes likewise. Large spatial variability in plant-available moisture might have natural origin, perhaps resulting from intermittent, spatially heterogeneous rainfall. It will be 
appropriate if soil moisture is aggregated in combination with vegetation parameters. A parallel study (White et al., 1996) directly addressed this issue for the extreme case of convective rain falling in a semi-arid environment. White's study demonstrated that sufficiently large differences in soil moisture rarely, if ever, occur because the location of successive convective storms is random, and the size of individual storms is usually small compared to the amount of moisture that can be stored in the plants' rooting depth.

The current study reveals a natural situation where large spatial variability in plant-available soil moisture can compromise the use of an aggregate description of mixed vegetation cover. If patches of vegetation with markedly different rooting depths exist side by side, then prolonged rain-free periods can result in moisture shortage for the shorter-rooted vegetation, but not for the deeper-rooted vegetation. In the case of the Amazon river basin, such rain-free periods are not usually prolonged and, on the basis of the present study, their detrimental consequences when using aggregation equations is limited in any case. However, it is possible to envisage particular situations where this could be a more persistent problem. An example is the case of freely transpiring, riparian vegetation in a semi-arid environment growing alongside persistently flowing streams which are sustained by groundwater or distant mountain headwaters. In such extreme situations it is perhaps necessary to find a way to aggregate soil moisture and vegetation parameters in combination.

Notwithstanding the above comments, this study assumed that the BATS-specific aggregation rules given in Table 1 (with linear aggregation of stomatal resistance) are now sufficiently wellestablished to be applied in conjunction with remotely sensed land cover data. Accordingly, area- 
average values of BATS vegetation parameters were calculated for $2.8^{\circ} \times 2.8^{\circ}$ (CCM2) grids and $1^{\circ} \times 1^{\circ}$ (ISLSCP) grids across conterminous the United States using these aggregation rules with the USGS/EDC prototype land cover data set. The values of these aggregate-vegetation parameters were compared with those for the most common cover for each grid square. Significant differences were found in some key vegetation parameters such as aerodynamic roughness, minimum stomatal resistance, maximum and minimum leaf area indices, and albedo.

Stand-alone BATS model simulations were then performed using a 2-year-long time series of forcing variables from the ISLSCP CDROM data set. In general, the difference in fluxes calculated for aggregate cover and fluxes calculated for dominant cover was less than what might have been anticipated on the grounds of the differences in individual parameters. In some cases, the fact that there are often co-located differences in two or more parameters perhaps helps to mitigate the net change in surface fluxes. Nonetheless, there were sizable regions of the USA where significant changes in calculated surface energy fluxes occurred in response to the different procedures for assigning vegetation parameters in the BATS model.

Further research is required to evaluate whether the difference in surface fluxes given by using aggregate (as opposed to most-common cover) parameters has a significant influence on modeled climates given by GCMs. However, global application of aggregation rules to improve GCM performance (in conjunction with upcoming remotely sensed AVHRR Path-Finder and EOS MODIS data sets) is at this stage arguably more profoundly limited by shortcomings in the validation of the cover class-specific values of vegetation parameters used, for example, in BATS. There is an urgent need to make effective use of the data now available from field sites 
around the world (for evergreen needleleaf forest, savannah grasslands, semi-desert, marsh land, short grass, and crops) to define the value of parameters for individual cover classes.

\section{Acknowledgments}

We are grateful to Robert Dickinson and Eleanor Blyth, who respectively provided us with the BATS and the ABL model, and to John Gash and Tom Loveland for respectively providing the ABRACOS and the USGS/EDC Land cover data sets. We also acknowledge many scientists who acquired and distributed the ISLSCP "Initiative 1", USGS-EROS land cover and the ABRACOS data sets and, in particular, Ivan Wright, for his help and advice during this study. We would also like to thank Soroosh Sorooshian, Cary White, Jaime Garatuza and Jean Morrill and for their help and encouragement throughout. We are thankful to Corrie Thies for her editorial assistance. The research described in this paper was carried out under NASA grant number NAG5-3824.

Z.L. Yang was partially supported under NASA EOS Interdisplinary Scientific Research Program (U.P.N 428-81-22 and U.P.N 429-81-22). Altaf M. Arain was partially supported by the Ministry of Science and Technology, Pakistan and NASA Global Change Research Fellowship (NGT - 30303). 


\section{REFERENCES}

Arain M.A., Michaud J., Dolman A.J., and Shuttleworth W.J., 1996: Testing of vegetation aggregation rules applicable to the Biosphere-Atmosphere Transfer Scheme and the FIFE site. J. Hydrol., 177:1-22.

Arain, M.A., 1994: Spatial aggregation of vegetation parameters in a coupled land surface-atmosphere model, M. S. thesis. University of Arizona, 150 p.

Blondin, C., 1991: Parameterization of land-surface processes in numerical weather prediction. Land Surface Evaporation: Measurement and Parameterization, T. J. Schmugge and J. C. André, Eds., Springer, 31-54.

Blyth, E.M., Dolman, A.J., and Wood, N., 1993: Effective resistance to sensible and latent heat flux in heterogeneous terrain. Q. J. R. Meteorol. Soc., 19: 423-442.

Clapp, R.B., and Homberger, G.M., 1978: Empirical equations for some soil hydraulic properties. Wat. Resour. Res., 14: 601-604.

Dickinson, R.E., Henderson-Sellers, A., and Kennedy, P.J., 1993: Biosphere-Atmosphere Transfer Scheme (BATS) version le for the NCAR Community Climate Model. Tech. Note NCARTN-387+STR. Natl. Cent. for Atmos. Res., Boulder, Colo., 72 p.

Gash, J.H.C., Nobre, C.A., Roberts, J.M., and Victoria, R.L., 1996: An overview of ABRACOS, in Amazonian Deforestation and Climate, (Eds. J.H.C. Gash, C.A. Nobre, J.M. Roberts, and R.L. Victoria) John Wiley, Chichester, 611 p.

Hodnett, M.G., de Silva, L.P., da Rocha, H.R. and Senna, R.C., 1995: Seasonal soil water storage change beneath central Amazonia rainforest and pasture. J. Hydrol., 170: 233254.

Koster, R.D and Suarez, M.j., 1992: A comparative analysis of two land surface heterogeneity representation. J. Climate, 5(12): 1379-1390.

Lhomme, J.P., Chehbouni A., and Monteny B., 1994: Effective parameters of surface energy balance in heterogeneous landscape. Bound. Layer Met., 71: 297-309.

Loveland, T.R., Merchant, J.W., Ohlen, D.O., and Brown, J.F., 1991: Development of a land cover characteristics database for the conterminous United States. Photogrammetric Engineering and Remote Sensing, 57(11): 1453-1463.

Lynn, B.H., Rind, D., and Avissar, R., 1995: The impact of mesoscale circulations generated by subgrid-scale landscape heterogeneities in general circulation models. $J$. Climate, 8(2): 191-205. 
Mason, P.J., 1988: The formation of areally-averaged roughness lengths. Q.J.R. Meteorol. Soc., 114: 399-420.

Mason, P.J., and Sykes, R.I., 1980: A two-dimensional numerical study of horizontal roll vortices in the neutral atmospheric boundary layer. Q.J.R. Meteorol. Soc., 106: 351366.

Meeson, B.W., Corprew, F.E., McManus, J.M.P., Myers, D.M., Closs, J.W., Sun, K. -J., Sunday, D.J., and Sellers, P.J., 1995: ISLSCP Initiative I-Global Data Sets for LandAtmosphere Models, 1987-1988. Volumes 1-5. Published on CD by NASA (USA_NASA_GDAAC_ISLSCP_001-USA_NASA_GDAAC_ISLSCP_005).

Monteith, J.L., 1965: Evaporation and the environmet, Symp. Soc. Expl. Biol., 19: 205234.

Nepstad, D.C., de Carvalho, C.R., Davidson, E.A., Jipp, P.H., Lefebvre, P.A., Negreiros, G.H., de Silva, E.D., Stone, T.A., Trumbore, S.E., and Vieira, S., 1994: The role of deep roots in the hydrological and carbon cycles of Amazonian forests and pastures. Nature, 372: 666-669.

Noilhon, J., and Lacarrére, P., 1995: GCM gridscale evaporation from mesoscale modeling. J. Climate 8(2): 206-233.

Raupach, M.R., and Finnigan, J.J., 1995: Scale issues in boundary-layer meteorology: surface energy balance in heterogeneous terrain. Hydrological Processes, 9: 589-612.

Riegel, C.A., 1974: Comments on "A simple but accurate formula for the saturation vapor pressure over liquid water". J. Appl. Meteor., 13: 606-607.

Roberts, J.M., Cabral, O.M.R., and Aguiar, L. de F., 1990: Stomatal and boundary-layer conductances in an Amazonian terre firme rainforest. J. Appl. Ecol., 27: 336-353.

Sellers, P.J., Meeson, B.W., Closs, J., Collatz, J., Corprew, F., Dazlich, D., Hall, F.G., Kerr, Y., Koster, R., Los, S., Mitchell, K., McManus, J., Myers, D., Sun, K.-J., and Try, P., 1995: An Overview of the ISLSCP Initiative I Global Data Sets. On: ISLSCP Initiative I-Global Data Sets for Land-Atmosphere Models, 1987-1988. Volumes 1-5. Published on CD by NASA. Volumel:USA_NASA_GDAAC_ISLSCP_001, OVERVIEW.DOC.

Sellers, P.J., Hall, F.G. Asrar, G., Strebel, D.E. and Murphy, R.E., 1992: An overview of the First International Satellite Land Surface Climatology Project (ISLSCP) Field Experiment (FIFE). J. Geophys. Res., 97(D17): 18345-18371.

Shuttleworth, W.J., Gash, J.H.C., Roberts, J.M., Nobre, C.A., Molion, L.C.B., and Ribeiro, M.N.G., 1991: Post-deforestation Amazonian climate: Anglo-Brazilian research to improve prediction. J. Hydrol., 129: 71-085. 
Shuttleworth, W.J.,1991: The modellion concept. Rev. Geophys., 29(4): 585-606.

Shuttleworth, W.J., 1988: Evaporation from rainforest. Proc. R. Soc. Lond., 233: 321346.

Shuttleworth, W.J., Gash, J.H.C., Lloyd, C.R., Moore, C.J., Roberts, J.M., Marques Filho, A. de O., Fisch, G., Silva Filho, V. de P., Ribeiro, M. de N.G., Molion, L.C.B., de Abreu Sa, L.D., Nobre, C.A., Cabral, O.M.R., Patel, S.R. and de Moraes, J.C., 1984: Observations of radiation exchange above and below Amazonian forest. Quart. J. R. Meteorol. Soc., 110: 1143-1162.

Wilson, M.F., 1984: The construction and use of land surface information in a general circulation climate model. Ph.D. dissertation, University of Liverpool, United Kingdom, $346 \mathrm{p}$.

Wood, N. and Mason, P.J., 1991: The influence of static stability on the effective roughness lengths for momentum and temperature. Q. J. R. Meteorol. Soc., 117: 10251056.

White, C.B., Houser P.R., Arain, A.M., Yang Z.L., Syed, K., and Shuttleworth W.J., 1996: The aggregate description of semi-arid vegetation with precipitation-generated soil moisture heterogeneity. Research in Hydrology and Earth System Sciences, (In press).

Wright, I.R., Gash, J.H.C., da Rocha, H.R., Shuttleworth, W.J., Nobre, C.A., Maitelli, G.T., Zamparoni, C.A.G.P., and Carvalho, P.R.A., 1992: Dry season micrometeorology of central Amazonian ranchland. Q. J. R. Meteorol. Sco., 118: 10831099.

Wright, I.R., Nobre, C.A., Tomasella, J., da Rocha, H.R., Roberts, J.M., Vertamatti, E., Culf, A.D., Alvala, R.C.S., Hodnett, M.G., and Ubarana, V., 1996: Towards a GCM Surface Parameterization for Amazonia. In Amazon Deforestation and Climate. (Eds. J.H.C. Gash, C.A. Nobre, J.M. Roberts, and R.L. Victoria) John Wiley, Chichester, 473-504 p. 


\section{Figure Captions}

Figure 1. (a) and (b) show a comparison between sensible heat (Hs: dotted line) and latent heat (LE: full line) at the pasture site for July 21, 1991. The lines with symbols are observations, while lines without symbols are modelsimulated fluxes with minimum stomatal resistance of (a) $200 \mathrm{sm}^{-1}$ and (b) $40 \mathrm{sm}^{-1}$, respectively. (c) and (d) show net radiation ( $\mathrm{Rn}$ : broken line) and modeled latent heat (LE: full line) at the forest site. (c) was a day with significant moisture shortage and (d) was a day without moisture shortage. The lines without symbols are modeled fluxes with $1.5 \mathrm{~m}$ deep roots mainly concentrated near the surface, while lines with symbols are with $4 \mathrm{~m}$ deep roots more equitably distributed.

Figure 2. Comparison of surface fluxes at 10:00 a.m. on October 30, 1990 displayed as a function of position across the 2000 -m wide modeled domain. In each case, the full line is the flux calculated with representation of distinct patches of pasture and forest, with the forest patch lying between 500 and $1500 \mathrm{~m}$, and the broken line is the average value of these same fluxes across the domain. The dotted line is the flux calculated with aggregate vegetation covering the entire domain.

Figure 3. Comparison of area-average surface fluxes calculated by the BATS-ABL model for the ABRACOS site with aggregate representation and explicit representation for patches of forest and pasture. These calculations were made at three times of day on five days using BATS vegetation parameters which had been slightly revised to enhance the agreement between observed and model-calculated fluxes.

Figure 4. (a) Calculated latent heat (LE: lines without symbol) and sensible heat (Hs: lines with symbol) given by stand-alone BATS models for the period, October 14, 1990 to November 1, 1990 when there were dry soils. In each case, the full line is the area-average flux with separate modeling of equal areas of forest and pasture, while the broken line is the aggregate representation of these two covers. (b) is similar to (a) except calculations are made for the period 12 January, 1991 to 31 January 1991 when there were moist soils. (c) Soil moisture wilting factors calculated by the standalone BATS model for the complete study period from October 4, 1990 to September 20, 1991 for upper and root zone soil layers using observed soil moisture for both pasture and forest site.

Figure 5. Comparison of the calculated fluxes given with three alternative aggregation rules for minimum stomatal resistance on (a) October 30, 1990 (a day with very dry soils), and (b) August 28, 1991 (a day with wet soils). Calculated latent heat (LE) fluxes are shown with the lines without symbols, and sensible heat (Hs) fluxes are shown with lines with crosses. 
Figure 6. Percentage difference in BATS-relevant vegetation parameters derived from the USGS/EDC data set using aggregation rules applied to $2.8^{\circ} \mathrm{x}$ $2.8^{\circ}$ (CCM2) grid squares over the conterminous USA relative to the equivalent value for the single most common BATS cover class in each grid square. The separate figures respectively correspond to the following parameters: (a) vegetation cover fraction; (b) minimum stomatal resistance; (c) albedo (average of visible and near infrared range); (d) warm season (maximum) leaf area index; (e) cool season (minimum) leaf area index; and (f) aerodynamic roughness length.

Figure 7. Same as Figure 6 but for $1^{\circ} \times 1^{\circ}$ (ISLSCP) grid squares.

Figure 8. Calculated values of surface heat fluxes given by applying the ISLSCP forcing data to a two-dimensional array of stand-alone BATS models spanning the conterminous USA with parameters for the single most common cover class [(a), (c), (e), and (g)] and for aggregate-cover [(b), (d), (f), and (h)]. The top four figures [(a), (b), (e), and (f)] are average values for the months of June, July and August 1988, while the bottom four figures [(c), (d), (g), and (h)] are average values for December 1987 and January and February 1988.

Figure 9. Difference between the calculated values of surface heat fluxes shown in Figure 8 using parameters for most common cover minus those parameters for aggregate cover. The figures (a) and (b) are for latent heat (LE), while the figures (c) and (d) are for sensible heat (Hs). The top two figures [(a) and (c)] are average values for the months of June, July, and August 1988, while the bottom two figures [(b) and (d)] are average values for December 1987 and January and February 1988.

Figure 10. Monthly average values of latent heat (LE) and sensible heat (Hs) for 1987 and 1988 calculated with a stand-alone BATS model forced with ISLSCP CDROM data using aggregate-cover parameters (shown with a symbol) and most common cover parameters (shown without symbol) for a $1^{\circ} \times 1^{\circ}$ ISLSCP grid square (a) in Kansas and (b) in southern Arizona. 

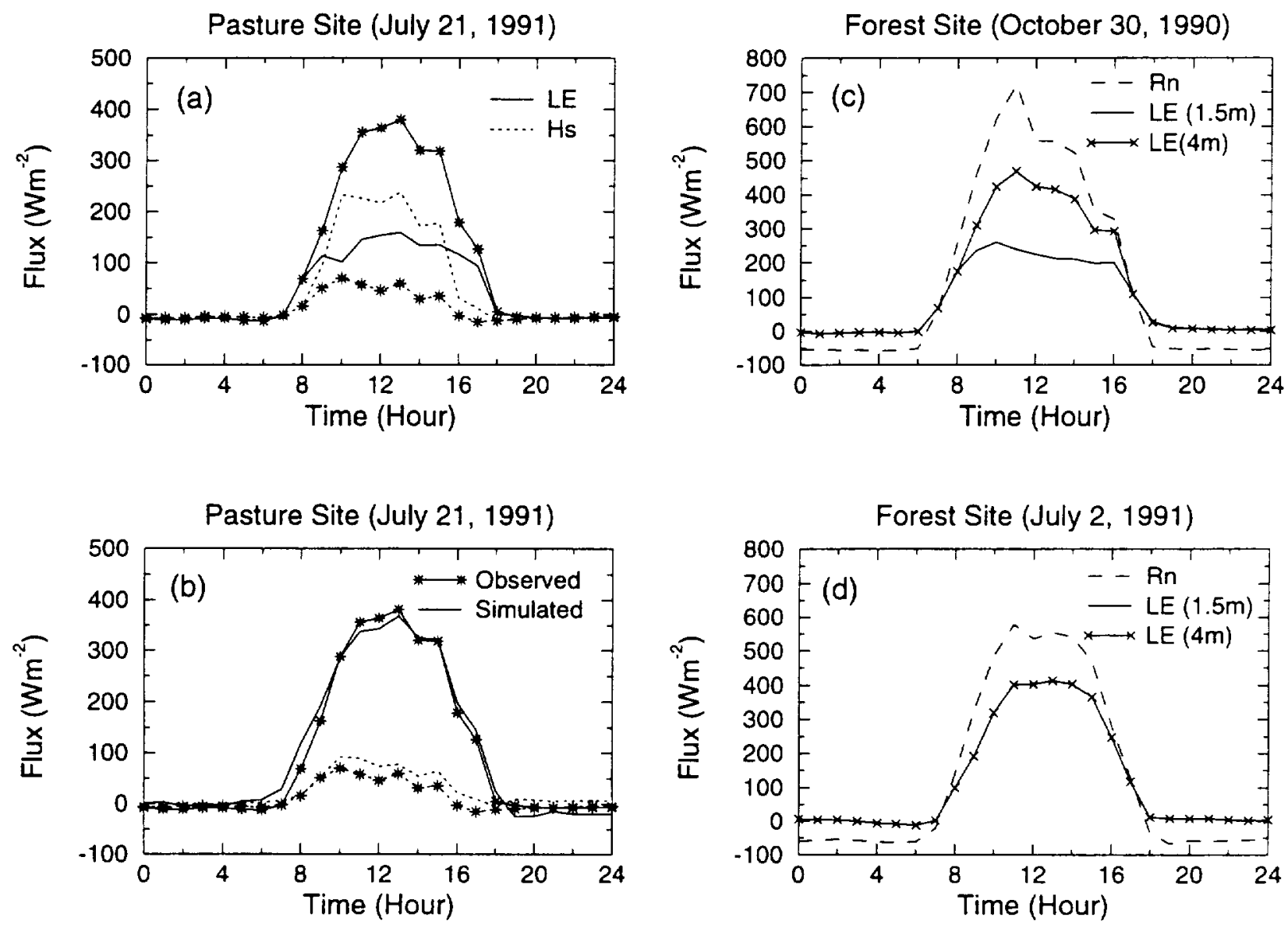

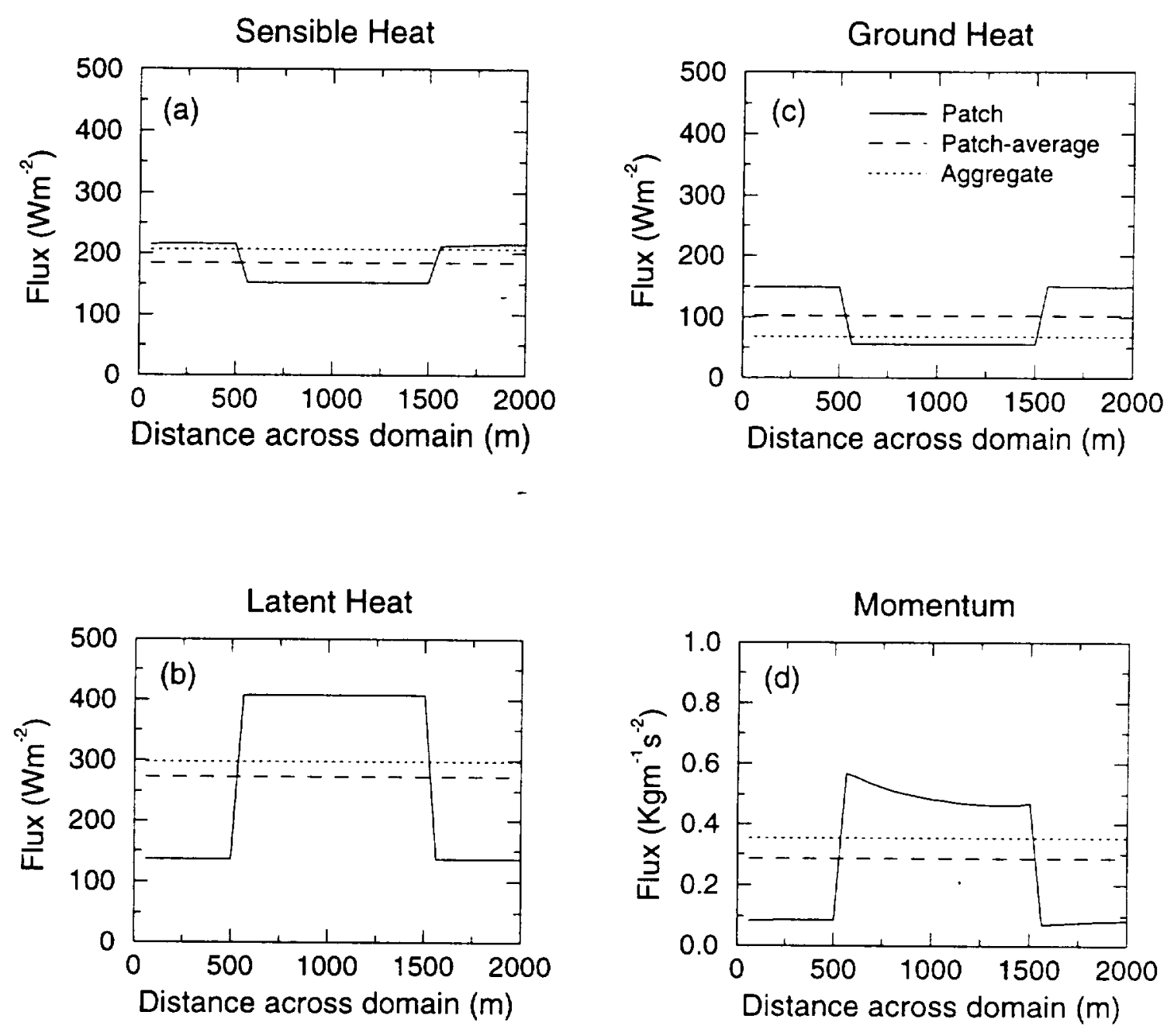

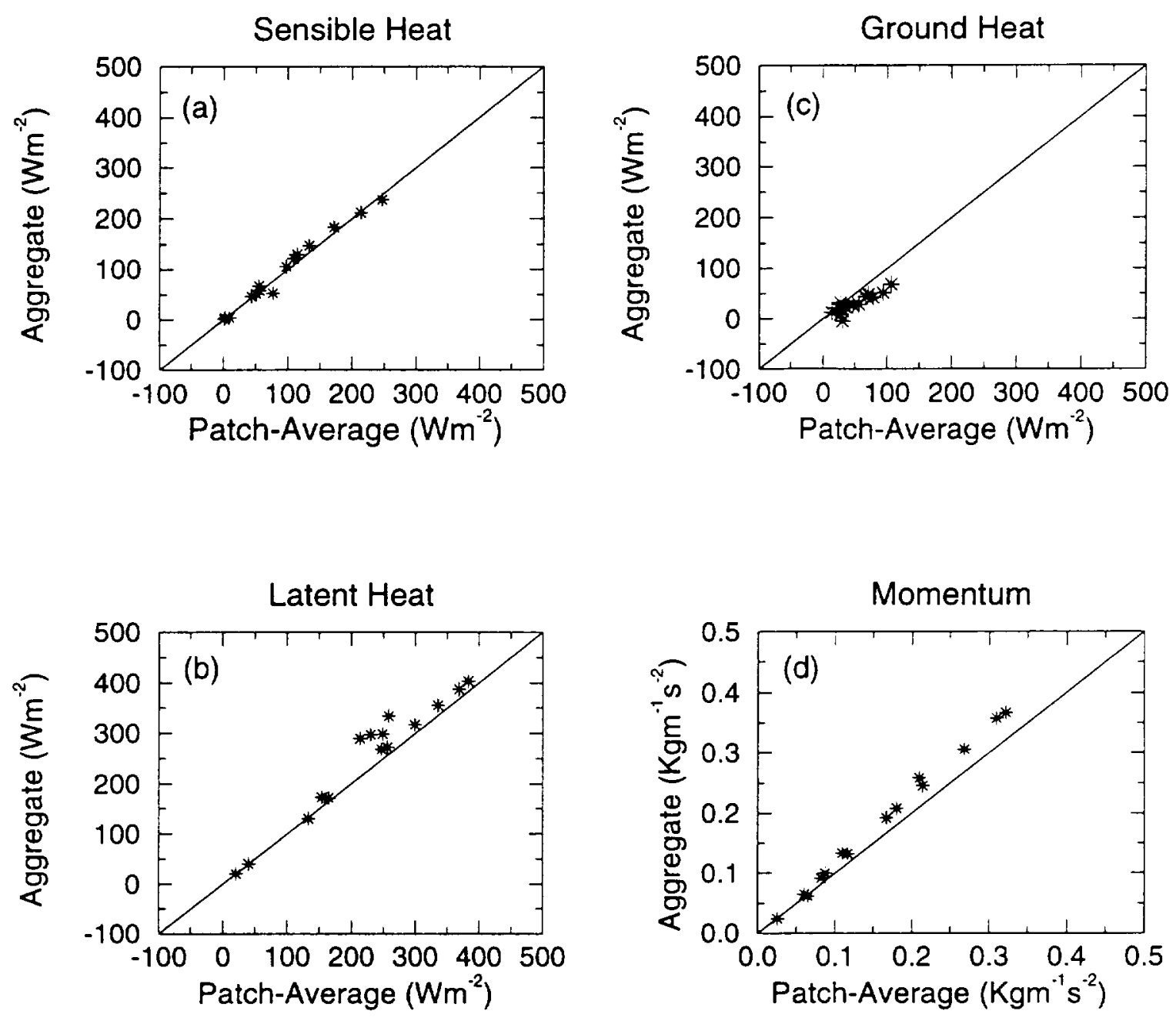

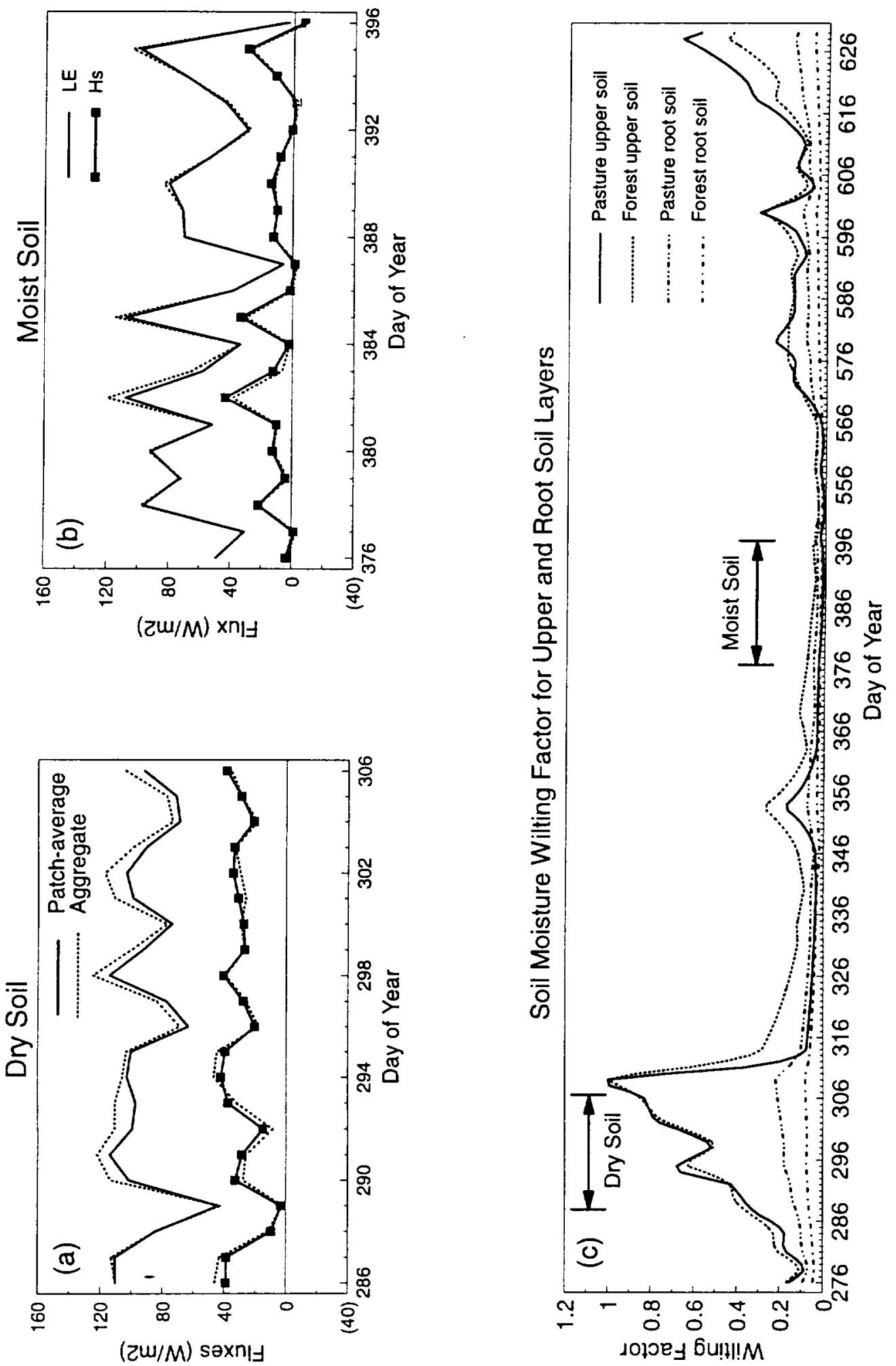

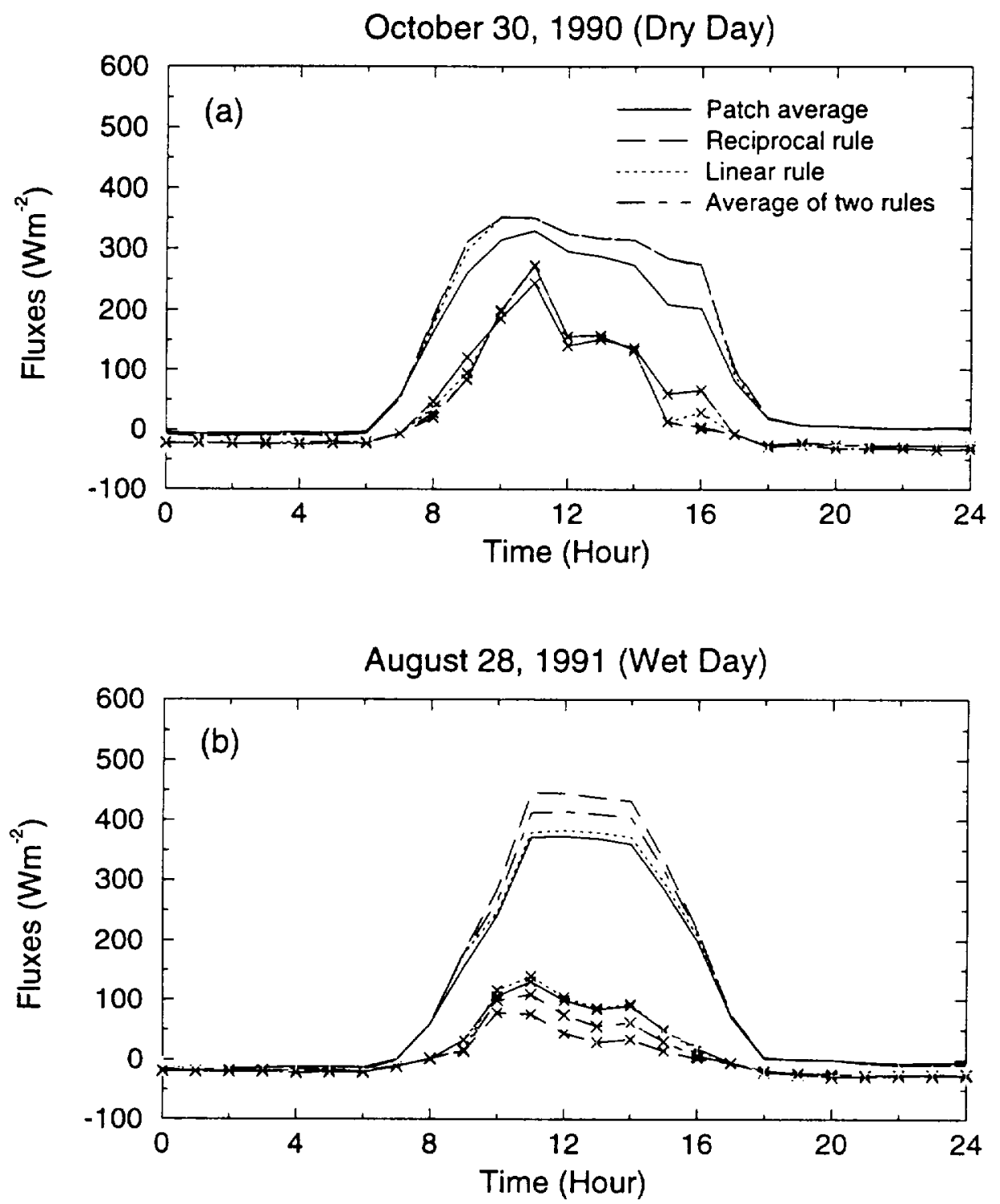

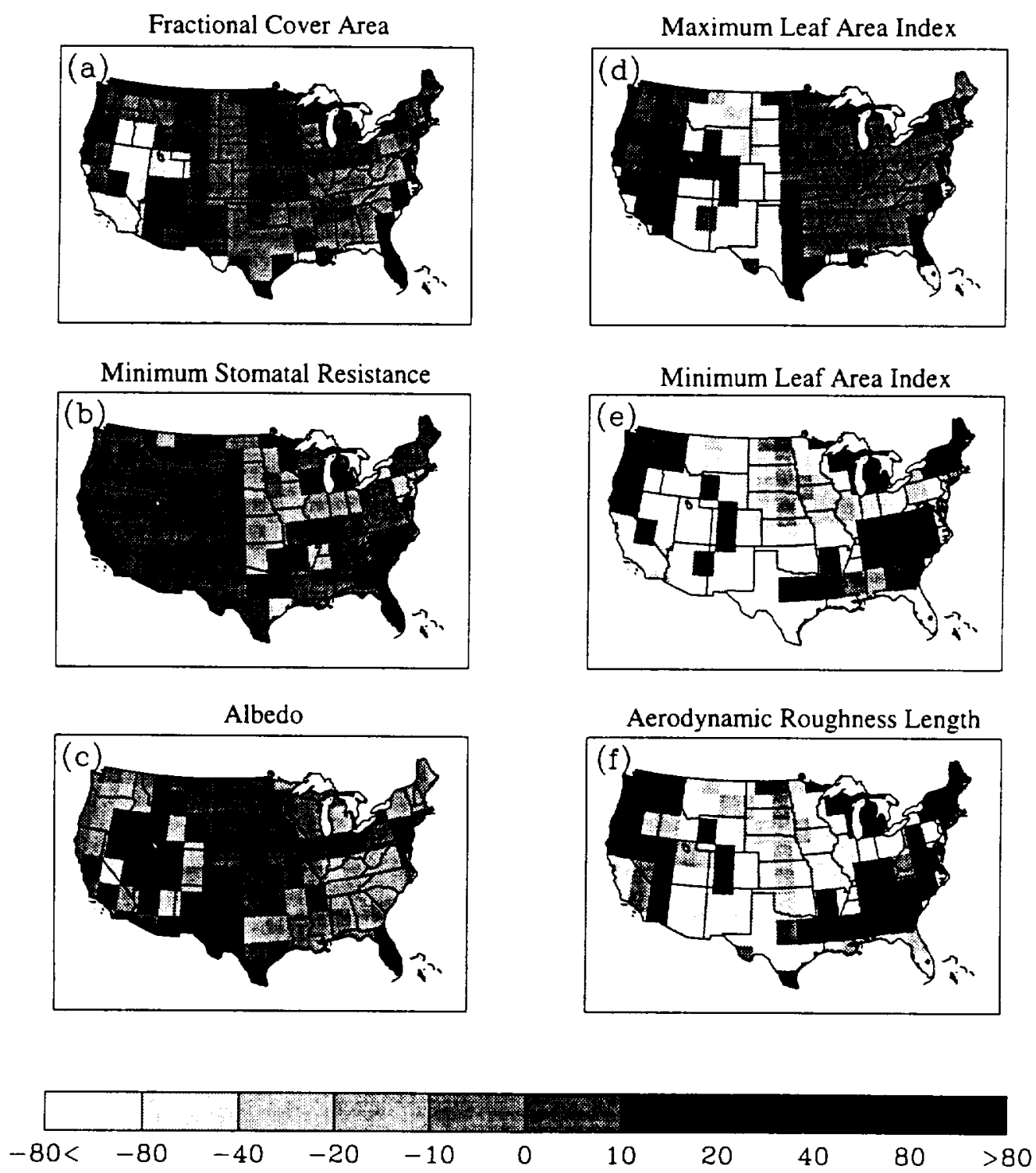

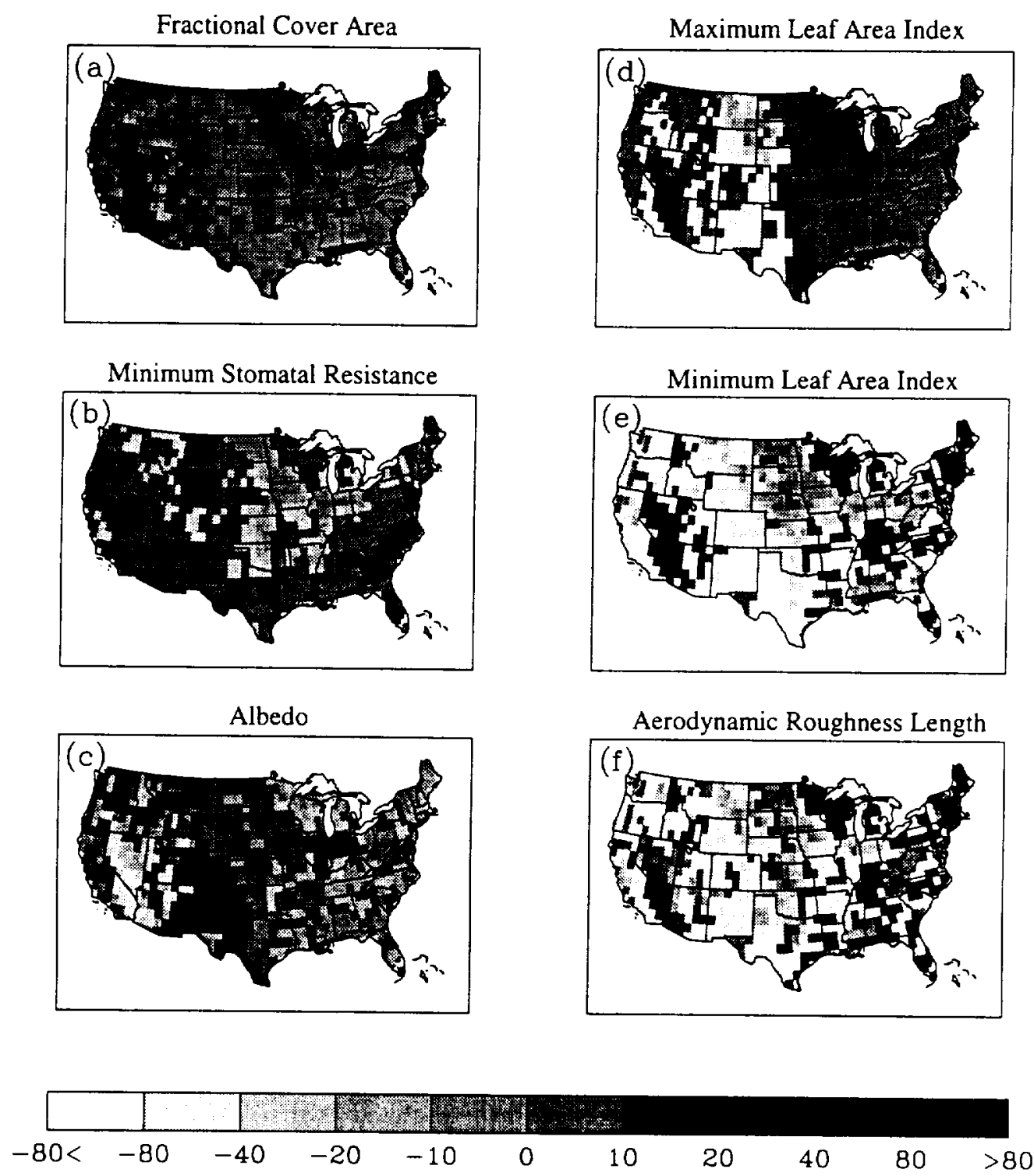
Latent Heat

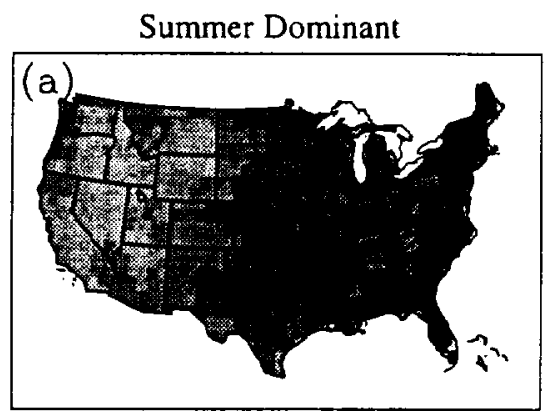

Summer Aggregate

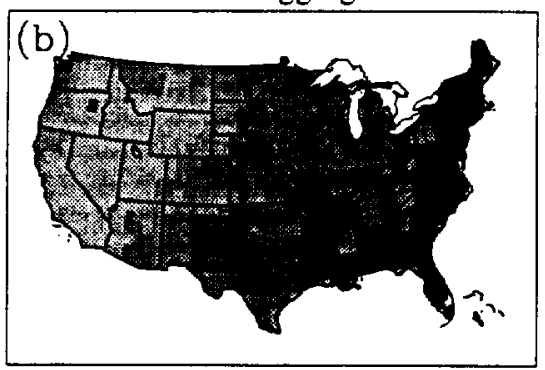

Winter Dominant

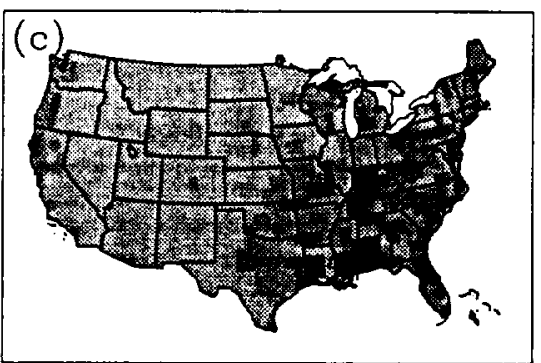

Winter Aggregate

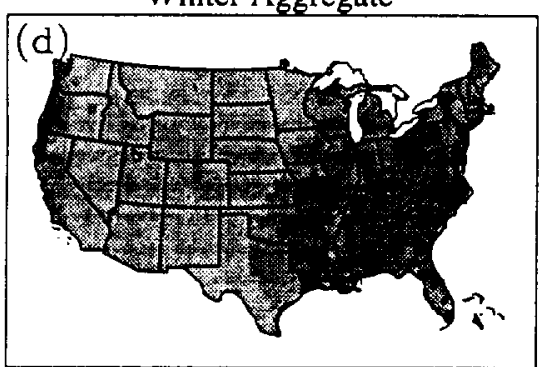

Sensible Heat
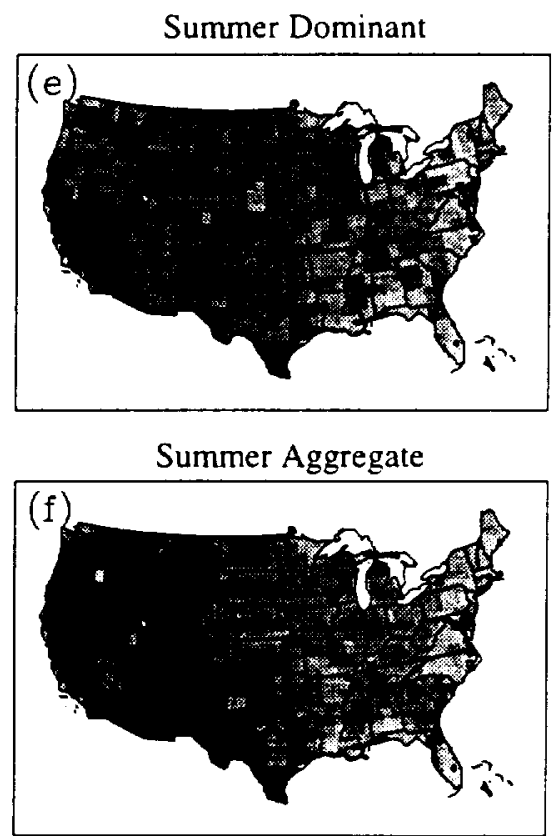

Winter Dominant

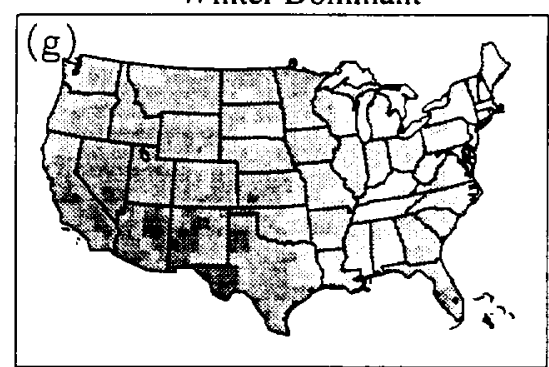

Winter Aggregate

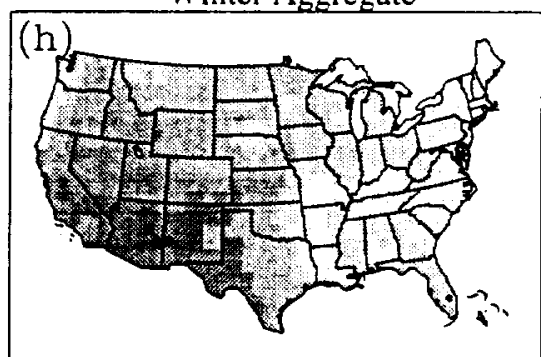

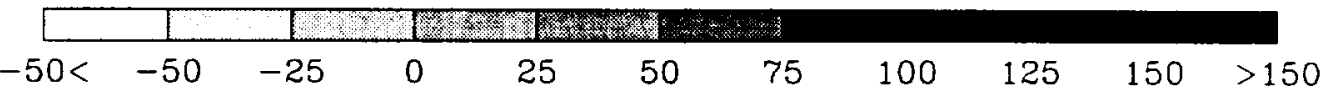

$\left(W / m^{\wedge} 2\right)$ 
Latent Heat

Summer
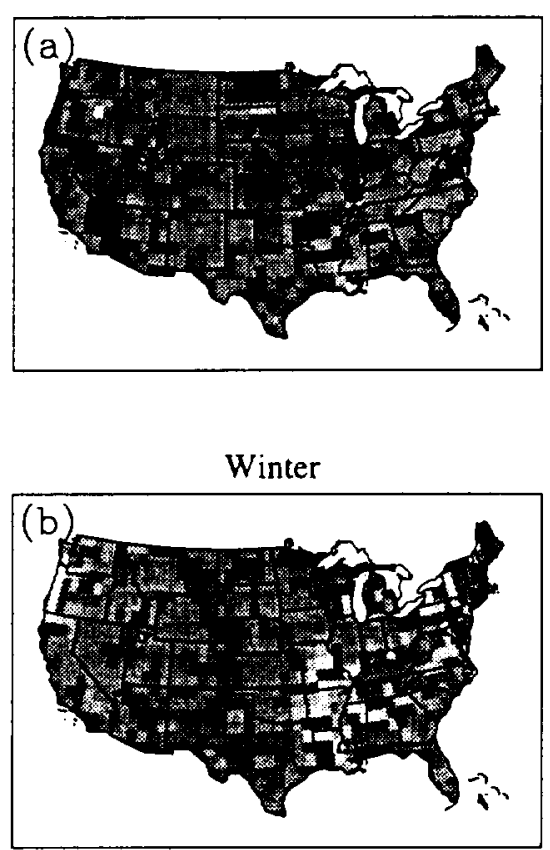

Sensible Heat

Summer

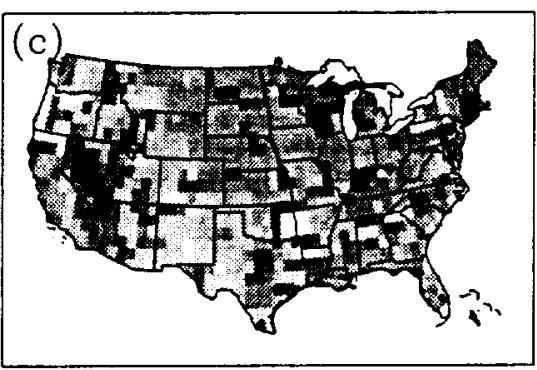

Winter

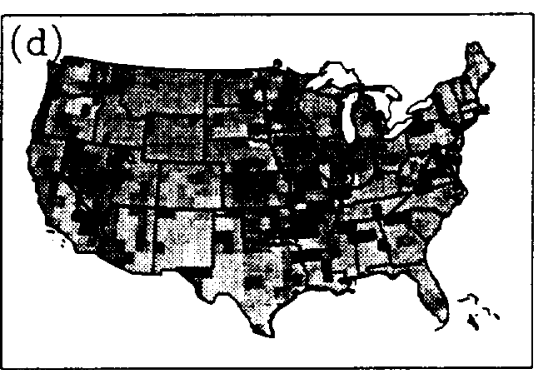

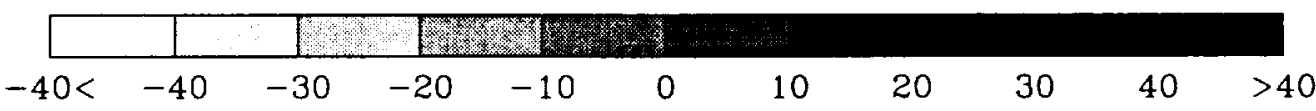

$\left(\mathrm{W} / \mathrm{m}^{\wedge} 2\right)$ 

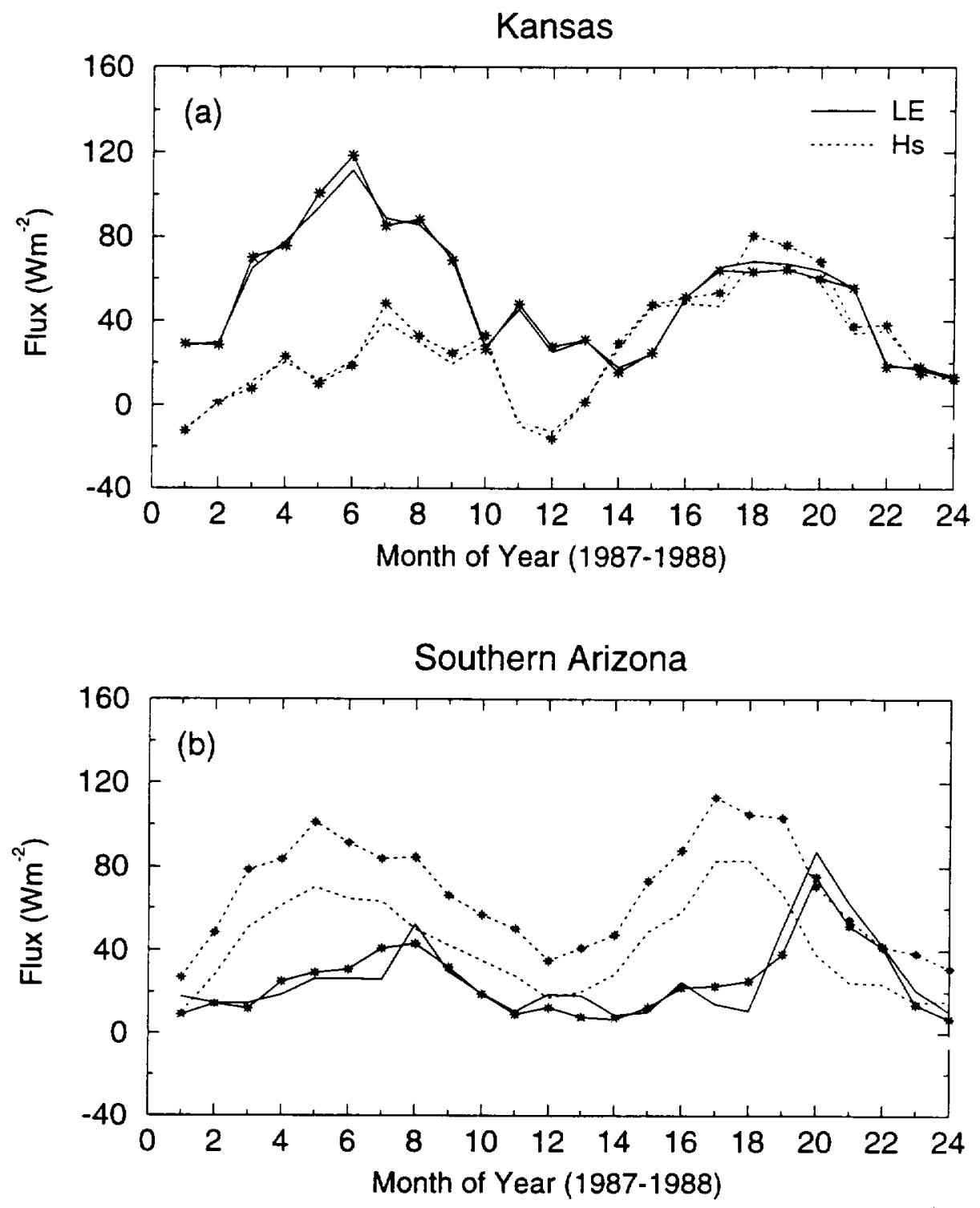


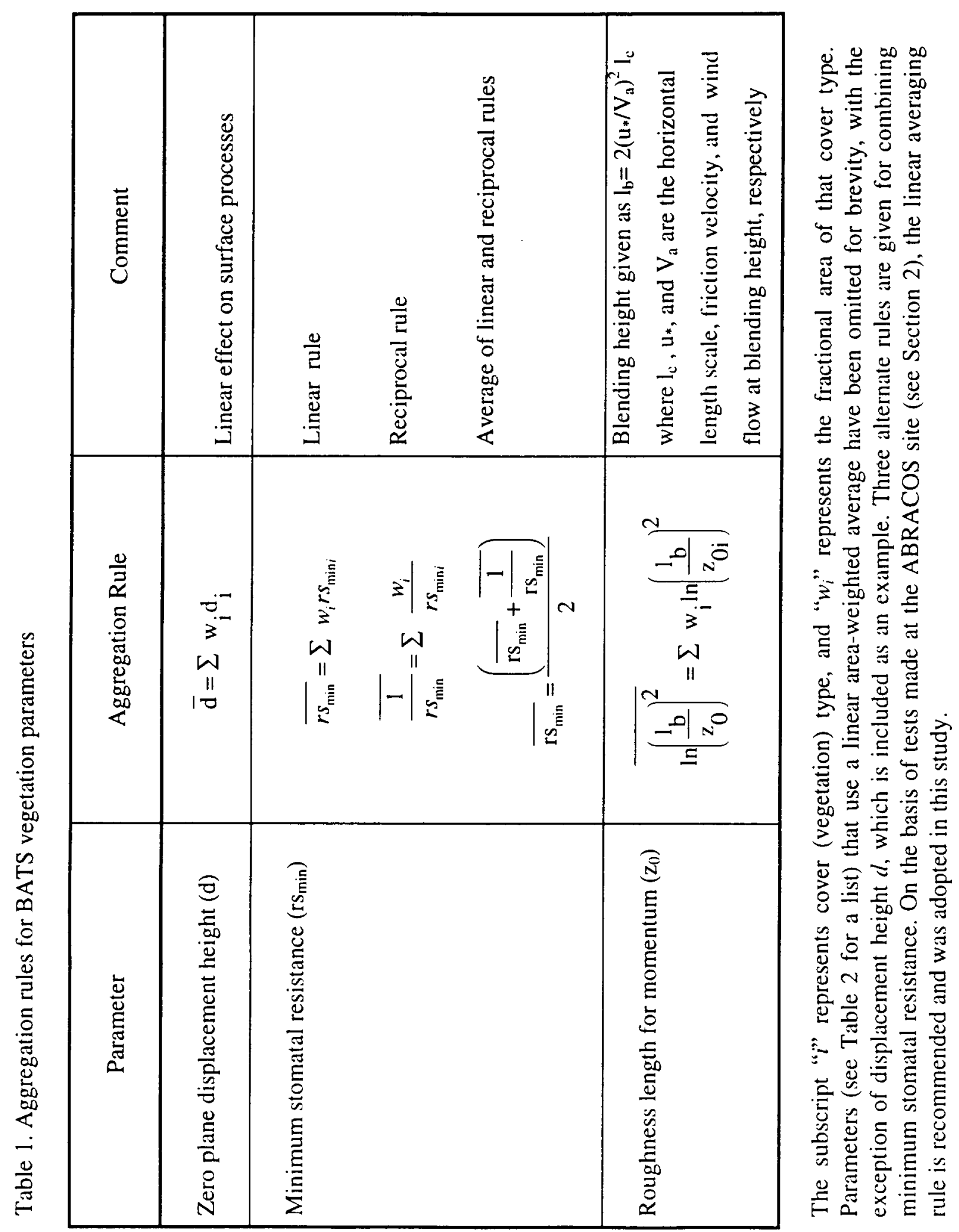




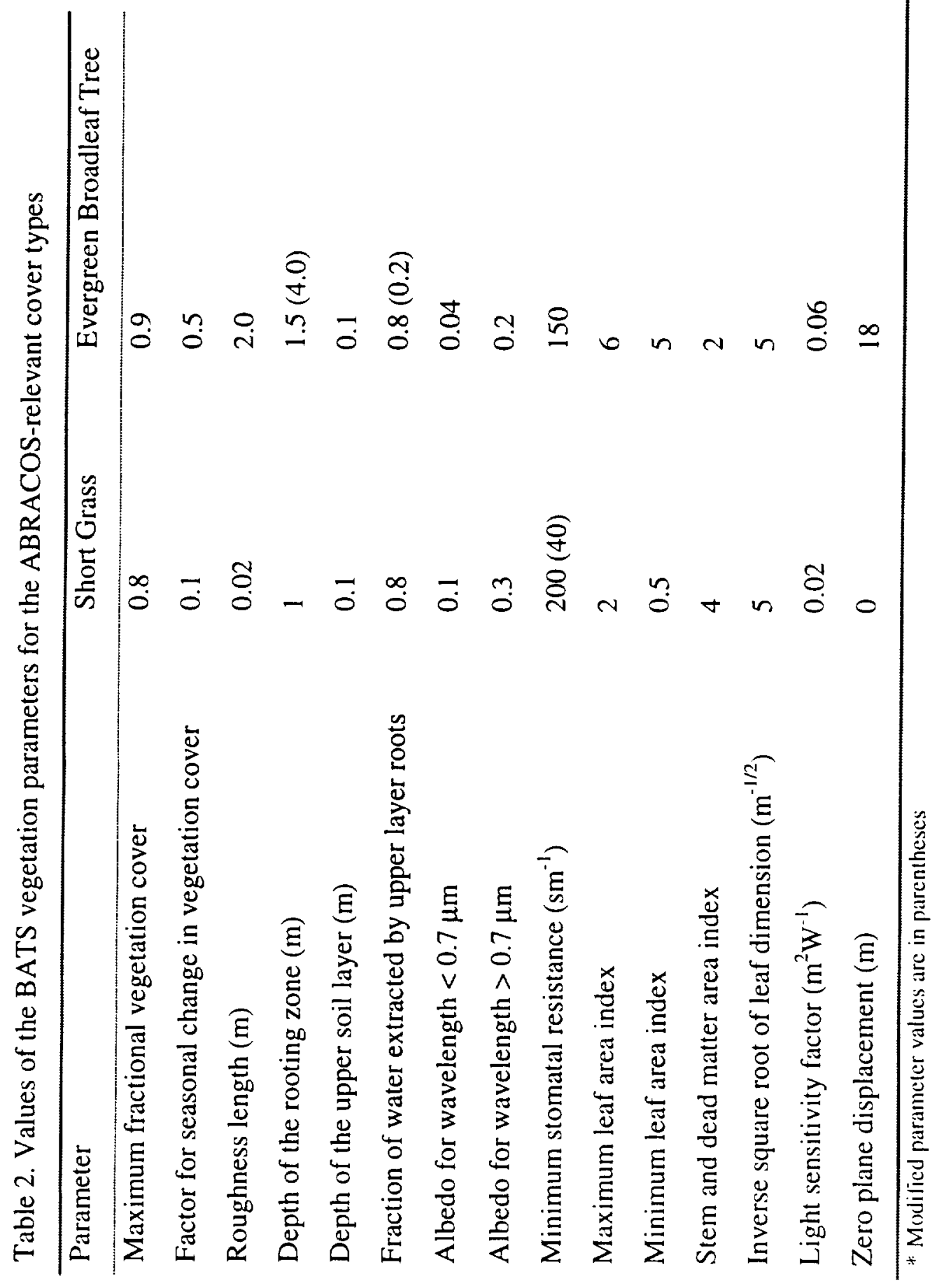


Table 3. BATS soil parameters used in ABRACOS study

(a) Soil texture parameters for class $\mathbf{1 0}$

\begin{tabular}{ll}
\hline Parameter & Value \\
\hline Porosity & 0.60 \\
Minimum soil suction (mm) & 200 \\
Saturated hydraulic conductivity (mm s & \\
Ratio of saturated thermal conductivity to that of loam & 0.0016 \\
Exponent B & 0.8 \\
Moisture content relative to saturation at which transpiration ceases & 0.487 \\
\hline
\end{tabular}

(b) Albedo for soil color class 7

\begin{tabular}{lc}
\hline Condition & Albedo \\
\hline Dry soil, wavelength $<0.7 \mu \mathrm{m}$ & 0.12 \\
Dry soil, wavelength $>0.7 \mu \mathrm{m}$ & 0.24 \\
Wet soil, wavelength $<0.7 \mu \mathrm{m}$ & 0.06 \\
Wet soil, wavelength $>0.7 \mu \mathrm{m}$ & 0.12 \\
\hline
\end{tabular}


Table 4. BATS state variables, driving variables, and parameters

\section{States}

Surface soil temperature $\left({ }^{\circ} \mathrm{K}\right)$

Subsurface temperature $\left({ }^{0} \mathrm{~K}\right)$

Temperature of foliage $\left({ }^{\circ} \mathrm{K}\right)$

Temperature of air within foliage $\left({ }^{0} \mathrm{~K}\right)$

Water in upper soil layer $(\mathrm{mm})$

Water in root zone soil (mm)

Total water in soil ( $\mathrm{mm})$

Ground wetness factor (fraction)

Dew on leaves (mm)

\section{Driving Variables (Boundary Inputs)}

Incident solar radiation $\left(\mathrm{Wm}^{-2}\right)$

Wind velocity $\left(\mathrm{ms}^{-1}\right)$

Air temperature at interface level $\left({ }^{\circ} \mathrm{K}\right)$

Specific humidity at interface level $\left(\mathrm{gKg}^{-1}\right)$

Precipitation (mm)

Surface pressure (mbar)

Downward longwave radiation $\left(\mathrm{Wm}^{-2}\right)$

\section{Parameters}

Interface height (m)

Vegetation parameters (see Table 2)

Land or sea flag

Soil texture parameters (see Table 3)

Soil color parameters (see Table 3 ) 
Table 5. Statistics for BATS validation at pasture site

(a) $r s_{\min }=200 \mathrm{sm}^{-1}$

\begin{tabular}{lccc}
\hline \multicolumn{1}{c}{ Flux } & $\begin{array}{c}\text { Mean Bias } \\
\left(\mathrm{Wm}^{-2}\right)\end{array}$ & $\begin{array}{c}\text { RMSE } \\
\left(\mathrm{Wm}^{-2}\right)\end{array}$ & Correlation Coefficient \\
\hline Latent heat & -38 & 82 & 0.90 \\
Sensible heat & +18 & 57 & 0.85 \\
Ground heat & -2 & 35 & 0.88 \\
Net radiation & -31 & 42 & 0.99 \\
\hline
\end{tabular}

(b) $\mathrm{rs}_{\min }=40 \mathrm{sm}^{-1}$

\begin{tabular}{lccc}
\hline \multicolumn{1}{c}{ Flux } & $\begin{array}{c}\text { Mean Bias } \\
\left(\mathrm{Wm}^{-2}\right)\end{array}$ & $\begin{array}{c}\text { RMSE } \\
\left(\mathrm{Wm}^{-2}\right)\end{array}$ & Correlation Coefficient \\
\hline Latent heat & -11 & 54 & 0.91 \\
Sensible heat & -4 & 40 & 0.80 \\
Ground heat & -1 & 33 & 0.89 \\
Net radiation & -24 & 36 & 0.99 \\
\hline
\end{tabular}


Table 6. Days and times for which aggregate and patch simulations were performed and observed soil moisture at corresponding mid-day time.

\begin{tabular}{|l|c|c|c|c|c|}
\hline \multicolumn{1}{|c|}{ Day of Year } & \multicolumn{3}{|c|}{ Time of day } & $\begin{array}{c}\text { Moisture in 0.1m } \\
\text { Soil Layer (mm) }\end{array}$ & $\begin{array}{c}\text { Moisture in } 1 \mathrm{~m} \text { Soil } \\
\text { Layer }(\mathrm{mm})\end{array}$ \\
\hline October 26, 1990 & $09: 00$ & $11: 00$ & $16: 00$ & 32 & 352 \\
\hline October 30,1990 & $08: 00$ & $10: 00$ & 13.00 & 30 & 345 \\
\hline December 10,1990 & $08: 00$ & $11: 00$ & $16: 00$ & 41 & 402 \\
\hline July 3, 1991 & $08: 00$ & $12: 00$ & $15: 00$ & 44 & 408 \\
\hline August 28, 1991 & $09: 00$ & $12: 00$ & $15: 00$ & 40 & 391 \\
\hline
\end{tabular}


Table 7. Mean latent heat (LE) and sensible-heat (Hs) fluxes over entire domain (conterminous USA) during summer and winter seasons using single dominant cover parameters and aggregate cover parameters. The values of maximum and minimum fluxes in any single $1^{\circ} \times 1^{\circ}$ grid square are also shown.

\begin{tabular}{|l|c|c|c|c|c|c|}
\hline & \multicolumn{3}{|c|}{ Summer Season } & \multicolumn{3}{c|}{ Winter Season } \\
\hline & Mean & Maximum & Minimum & Mean & Maximum & Minimum \\
\hline LE & 58.9 & 205.4 & 8.7 & 28.2 & 92.8 & -1.4 \\
\hline LE aggregate & 56.9 & 170.4 & 4.2 & 29.7 & 89.2 & 0.8 \\
\hline Hs & 68.3 & 135.3 & -37.5 & 0.6 & 53.8 & -47.5 \\
\hline Hs aggregate & 74.8 & 134.5 & 11.2 & 1.3 & 50.6 & -52.5 \\
\hline
\end{tabular}

